\title{
Finite Element Modeling of Ballistic Impact on a Glass Fiber Composite Armor
}

\author{
A Thesis \\ presented to \\ the Faculty of California Polytechnic State University, \\ San Luis Obispo \\ In Partial Fulfillment \\ of the Requirements for the Degree \\ Master of Science in Mechanical Engineering \\ by \\ Dan Davis \\ April 2012
}


(C) 2012

Dan Davis

All Rights Reserved 


\section{Committee Members}

Title:

Author:

Date Submitted:

Committee Chair:

Committee Member:

Committee Member:
Finite Element Modeling of Ballistic Impact on a Glass Fiber Composite Armor

Dan Davis

April 2012

Thomas Mackin, Professor, Mechanical Engineering

Joseph Mello, Professor, Mechanical Engineering

Saeed Niku, Professor, Mechanical Engineering 


\section{Abstract}

Finite Element Modeling of Ballistic Impact on a Glass Fiber Composite Armor Dan Davis

Experiments measuring the ballistic performance of a commercially available fiberglass armor plate were used to guide the development of constitutive laws for a finite element model of the impact. The test samples are commercially available armor panels, made from E-glass fiber reinforced polyester rated to NIJ level III. Quasi-static tensile tests were used to establish material properties of the test panels. These properties were then used to create models in the explicit finite element code LSDYNA. Ballistic impact testing of the panels was conducted using a compressed gas gun firing spherical steel projectiles oriented normal to the test panel surface. The $V_{50}$ ballistic limit of these panels was found to be approximately $560 \mathrm{~m} / \mathrm{s}$. Tuning parameters in the finite element models were adjusted to match the experimentally measured penetration depths and ballistic limits. Models were created in LSDYNA by adjusting the available material library types 3 and 59 for the target, and material type 15 for the projectile. Type 3 models are isotropic, and resulted in shear punch-out type failures of the plate that poorly replicated the test results. Type 59 takes orthotropic properties into consideration, and can analyze delamination when used with solid elements. Results with model type 59 were significantly better than those using type 3 , however, this model was found to vastly underestimate the impact resistance of the plate. With significant adjustments to the material properties in the type 59 model, the LSDYNA simulations were found to better replicate the experimentally observed response of the panels. However, these deformations are questionable since they required quite unrealistic adjustments to the material properties. 


\section{Contents}

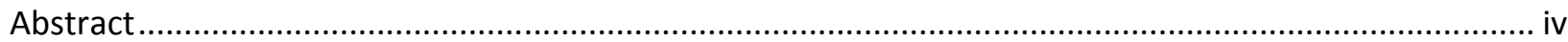

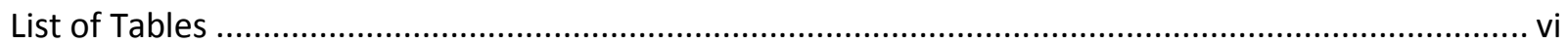

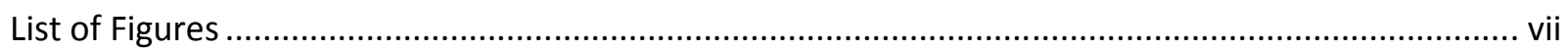

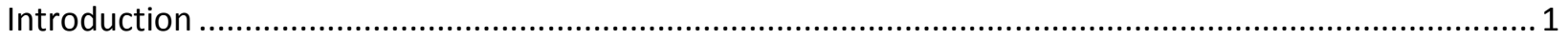

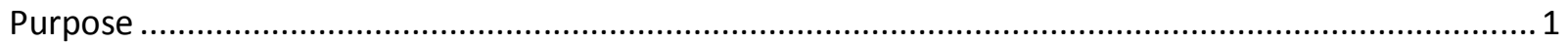

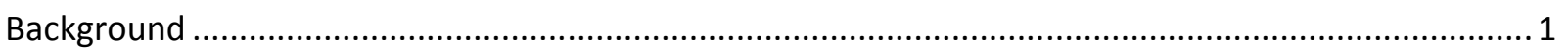

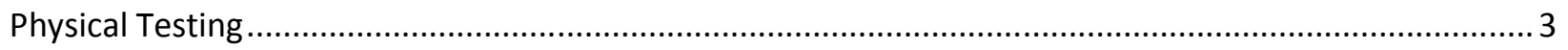

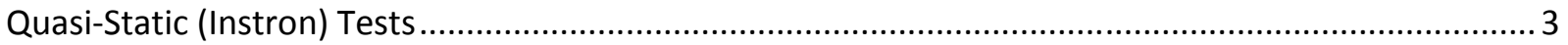

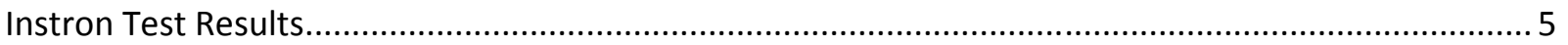

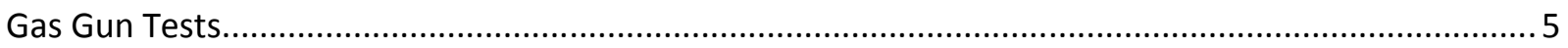

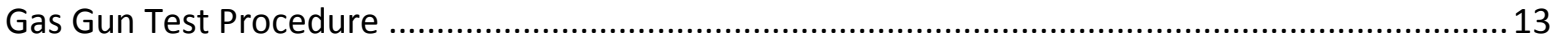

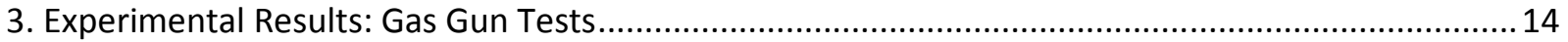

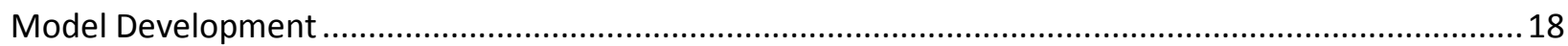

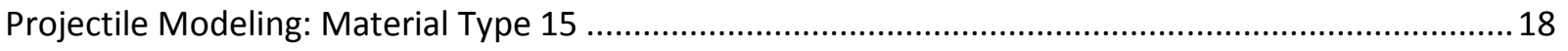

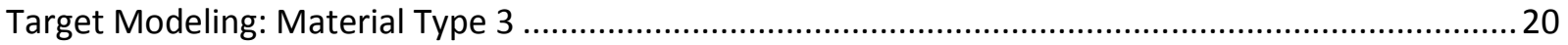

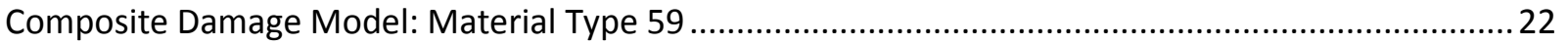

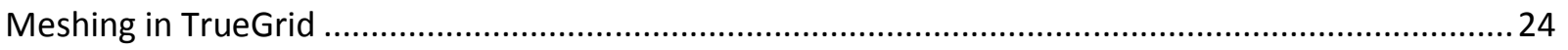

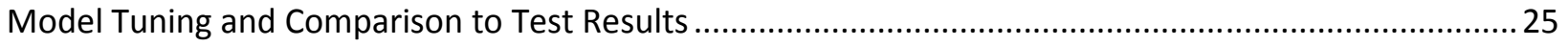

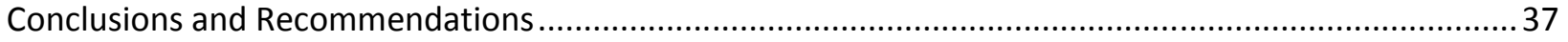

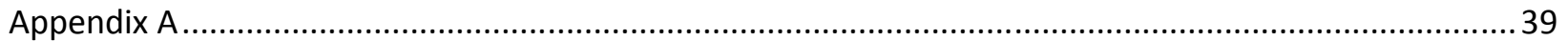

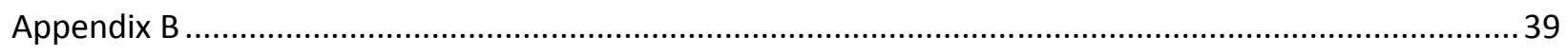

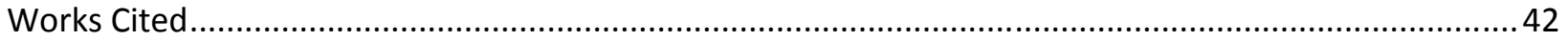




\section{List of Tables}

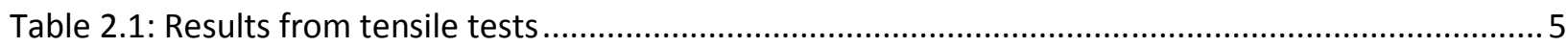

Table 2.2: Comparison of laser and videographical velocity measurements .........................................13

Table 3.1 Impact Velocity of Gas Gun Shots ....................................................................................... 14

Table 3.2: Embedded Depth of Projectiles that Partially Penetrated the Target .................................. 16

Table 4.1: Johnson-Cook Parameters for Steel used in the FEA Models ................................................. 19

Table 4.2: Gruneisen parameters used to the 304 equation of state. ................................................ 24

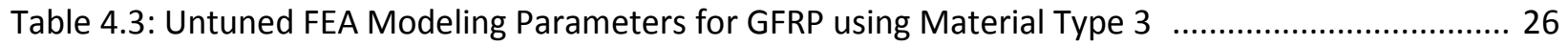

Table 4.4: Type 59 model properties. In this model, the first two rows define material moduli, the variables AOPT, MACF, and the 3rd and 4th rows define the material primary axes. The 5th row

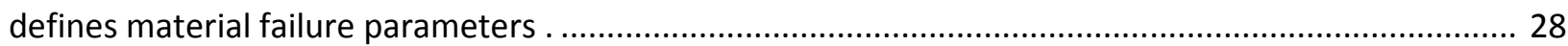

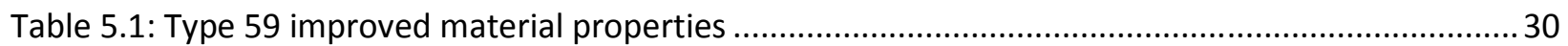




\section{List of Figures}

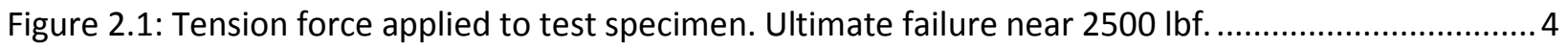

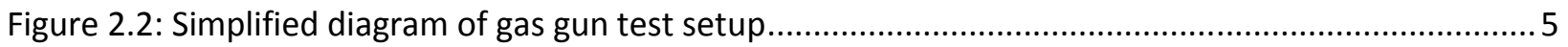

Figure 2.3: Photo of gas gun apparatus used in the testing of fiberglass targets ................................... 6

Figure 2.4: Clamping fixture used to hold targets for the gas gun. The target is represented in the model by the pink plate. Note that the cross-drilled gun muzzle is a separate part. CAD model

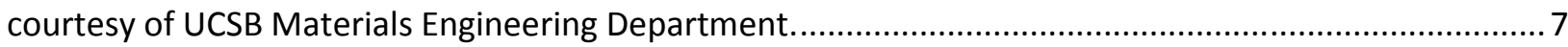

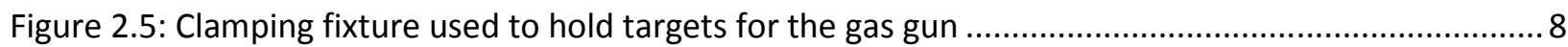

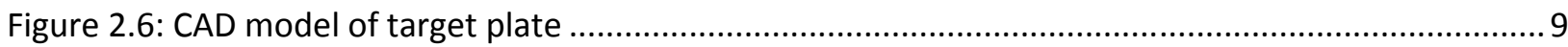

Figure 2.7: Projectile assembly, as inserted in the breach of the gas gun............................................ 10

Figure 2.8: Ruler used to calibrate distance as viewed by the high-speed camera................................... 11

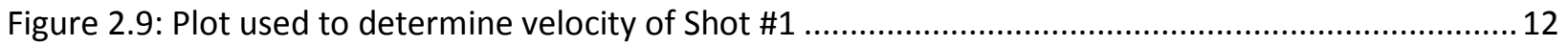

Figure 3.1: Impact tests over a range of velocities were used to determine the V50 for a fiberglass armor system. These tests also show that, following complete penetration, the exit velocity

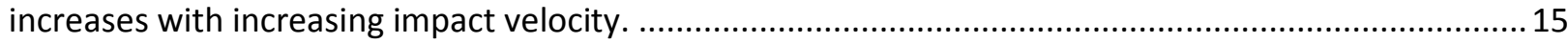

Figure 3.2: Penetration depth as a function of impact velocity for projectiles captured in the target.....17 Figure 4.1: Schematic stress-strain response courtesy of the LSDYNA Keyword Manual demonstrating the Tangent Modulus (Et) and Hardening Parameter $(\beta)$. The hardening parameter value may be

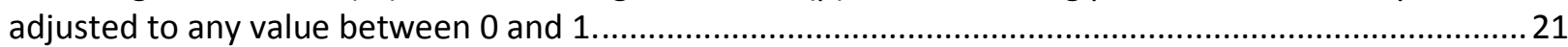

Figure 5.1: Both the sphere and the target were meshed using TrueGrid. ...........................................2 24

Figure 5.2: Type 3 target model $4.8 \mathrm{~ms}$ after impact shows limited plastic deformation in the target

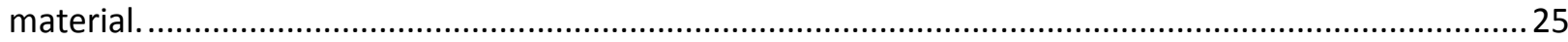

Figure 5.3 : Plot of deformation of the type 3 target at $\mathrm{t}=4.8 \mathrm{~ms}$ after impact. Section through $\mathrm{Y}-\mathrm{Z}$ mid-

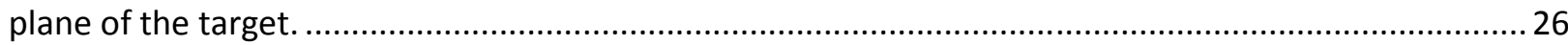

Figure 5.4: Projectile velocity as a function of time for the untuned type 3 model..............................26 Figure 5.5: LSDYNA simulations of ballistic impact of a stainless sphere and a type 3 plate show little permanent plastic deformation and do not match the experimentally observed response of the

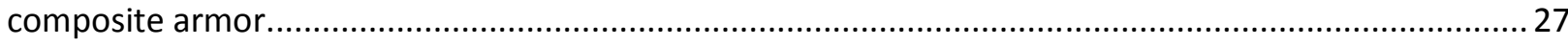

Figure 5.6: Fringes Showing Plastic Strain on the Type 59 Model with Untuned Material Properties.... 28

Figure 5.7: Velocity Plot for Type 59 Model with tuned properties...................................................29

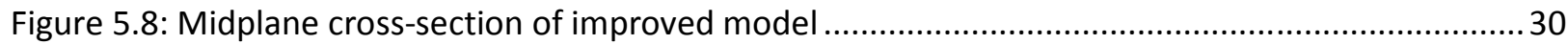

Figure 5.9: Material coordinate axes without INN. Notice how the primary material axes are forced to remain perpendicular, with the $x$-axis in line with the 1 and 2 nodes. This is not a realistic representation of fiber directions in the deformed material.

Figure 5.10: Same deformations as before, but with INN turned on. Material directions are now defined by element bisectors, improving accuracy.

Figure 5.11: Velocity plot for the projectile during and just after the impact event. Nearly all the slowing comes in the first $25 \mu \mathrm{s}$ after impact. Note that exit velocity is still well above the test value near zero.

Figure 5.12: Cut-away contour plot of the strain in the model. Note that a strain value of 1 is an undeformed element, while a strain of 0 would indicate a completely failed element. 
Figure 5.13: The simulated projectile deformation after $6 \times 10-5$ seconds is shown on the left, while the projectile from test shot number 8 is shown on the right. Clearly, the actual projectile experienced much less deformation.

Figure 5.14: Side view of modeled target deformation. Modeling parameters for the target and projectile have been changed significantly...... .36

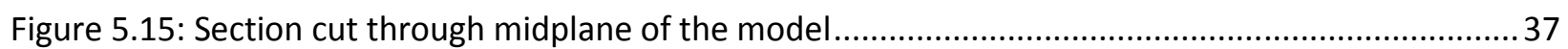

Figure 5.16: Section cut of midplane of model. Fringes show levels of plastic strain. ...............................37 


\section{Introduction}

\section{Purpose}

Physical testing of armor panels requires both expensive and specialized testing equipment that can produce realistic impact velocities as well as robust, high-speed data acquisition. If accurate, computer simulations could provide performance estimates and material screening prior to testing, significantly reducing both the time and cost required to develop armor systems. Experience has shown that these simulations are often unreliable if not tuned to experimental results. In fact, it is common practice to use actual test data to tune the simulations prior to relying on results of simulation as demonstrated in [1], [2], and [3]. Judicious application of simplified tests, however, can be carried out to validate and improve a given material model. That model could then be applied to other situations with a greater degree of confidence in the output.

\section{Background}

The potential weight advantages of fiber-reinforced plastics make them attractive candidates for armor applications. Selecting a composite system, however, can be a daunting prospect with numerous design iterations. To expedite the materials selection process other researchers have used LSDYNA or other explicit finite element codes to simulate high-speed impacts on fiber-reinforced plastics.[1], [2], [3] In some cases researchers have tried to model the individual fibers in the fabric by creating elements that follow the contours of the woven fabric yarns [4] and [1]. This approach clearly leads to a complex mesh geometry, which can be computationally intense and requires more time in solid modeling and meshing programs. If a continuum approximation of a composite can be made, much time could be saved. The goal of this research was to apply a simplified continuum model to the ballistic performance of a 
representative armor composite. Though such a model would not capture the entirety of the mechanisms active in the armor, the advantages of a simple method were believed worth the exercise.

The armor used in this test is composed of several layers of woven glass fabric embedded in a polyester matrix. Armor of this type is opaque, and is suitable for armoring doors, judge's benches, walls, and vehicles. Due to the relatively high thickness, lack of flexibility, and relatively modest stopping power, this armor is not commonly used in body armor applications.

In the United States, armor is typically rated on a scale published by the National Institute of Justice. The glass/polyester composite used in this study has been rated to NIJ Level III. This level of protection is intended to stop projectiles from most handguns. Examples include any variety of 9 millimeter, .357, and .44 calibers. According to the National Institute of Justice [5], additional armor would be required to provide acceptable protection against rifle rounds.

\section{Material Selection}

Selection of fiber type has significant impact on the properties of the resulting armor. Common choices include Fiberglass, Kevlar (and its various subtypes), and Ultra-High Molecular Weight Polyethylene (UHMWPE), which include Spectra and Dyneema. For this study, glass fibers were chosen for reasons of cost and simplicity. Due to the high shear resistance of Kevlar, this material is extremely difficult to cut with conventional tools, a problem that is even greater with UHMWPE fibers. Fiberglass can be cut easily with commonly available tools, such as drills, bandsaws, or tilesaws. This makes it easier to cut to shape for each user's particular application. Additionally, fiberglass is much less costly than either Kevlar or UHMWPE fibers. While there are some weight advantages to Kevlar, and even more so with UHMWPE, the cost increase may be difficult to justify, particularly in applications where weight is of little or no concern. Lastly, glass fibers have been in production much longer, providing a much more robust 
materials database. Material properties used in this study were based on those presented in [6] , [7], and [8]. These properties were used as a starting point when tuning the FEA models.

\section{Ballistic Limit}

According to the NIJ, the ballistic limit is defined for each particular projectile as the velocity for which the probability of penetration is 50\%, and is typically referred to as V50. [5] Finding the V0, or the velocity at which defeat of all projectiles is guaranteed, is difficult to do. Procedures for finding V50, as stated in MIL-SPEC-662, are far more common and easier to execute. [9] However, due to the results of the physical testing, it can be demonstrated that any projectile with an impact velocity equal to V50 which does penetrate the armor will have significantly reduced energy, and be less likely to cause serious damage or injury. For purposes of this study, the models we developed were intended to be tuned to impact velocities near the V50 of the material. This is logical since weight and cost concerns in a real-world application would likely drive the design so that expected impacts are not excessively far below the ballistic limit.

\section{Physical Testing}

\section{Quasi-Static (Instron) Tests}

Tensile samples, measuring about 0.2 inches thick by 1 inch wide and 5.5 inches long were cut using a diamond saw from large panels of 0.444 inch thick, as-received fiberglass armor plate. These samples were tested to failure in tension in an Instron test machine at a fixed crosshead speed of 0.001 inches per second. Displacement and load data were gathered using the data acquisition system built into the Instron testing machine. Tests were conducted on samples cut in both the 1-1 and 2-2 (in-plane) material directions. Since the layup of fabric was composed entirely of a balanced weave cloth in the 0/90 direction, these properties were expected to be the same in both directions. Since additional 
fixturing would have been required to perform thru-thickness tension tests in the 3-3 direction as well as to measure the shear properties, these tests were not conducted. It is recommended that these tests be conducted to support any future studies of this material.

Specimens were clamped directly in the jaws of the test machine, and pulled along the long axis at a constant rate of $0.001^{\prime \prime}$ per second. Data was acquired at a rate of $1000 \mathrm{~Hz}$. Figure 2.1 , below, shows a typical force-time graph from a tensile test in the 1-1 direction. Similar results were obtained from tests in the 2-2 direction. These tests were used to determine both the elastic modulus and the ultimate strength of the composite armor. The elastic modulus was measured by performing a linear curve fit from the point when the load was zero, up to a load of $522 \mathrm{lbs}$ for the test data shown below. This was felt to be a point well within the linear elastic region for this sample, as the load curve was still linear at this point.

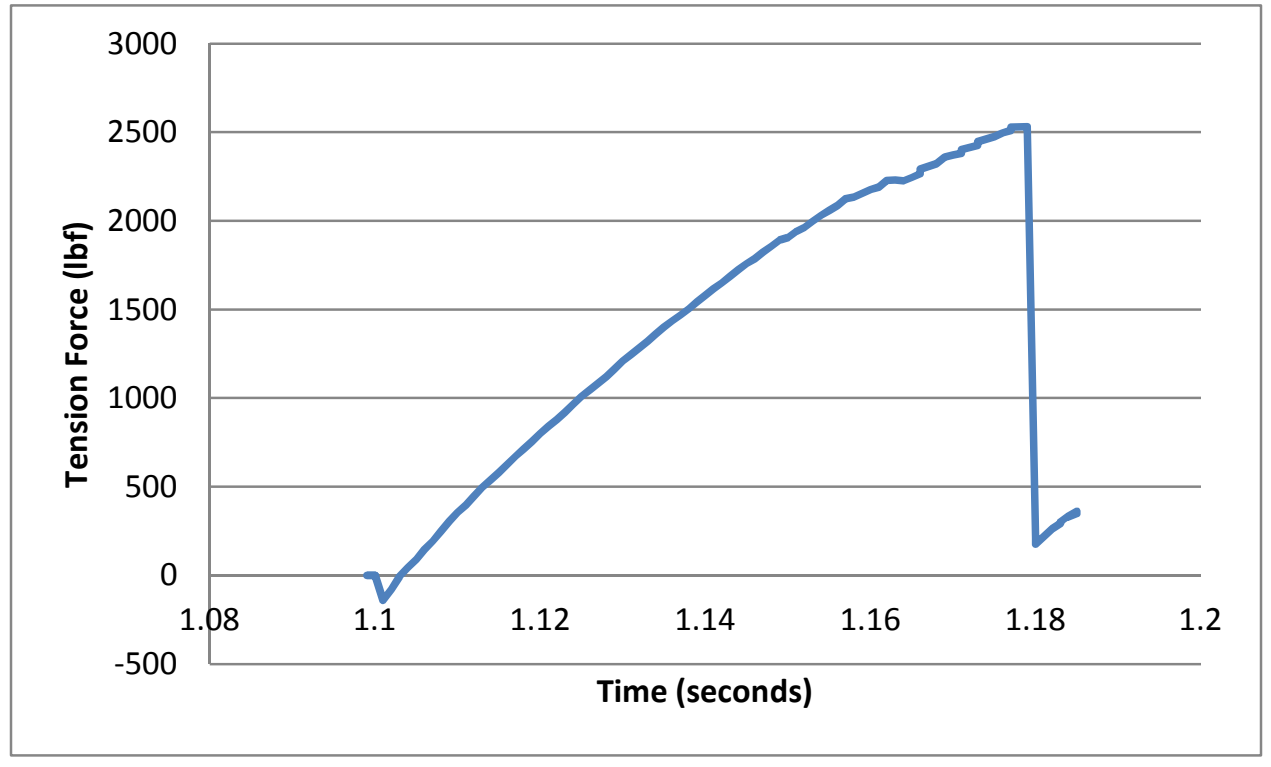

Figure 2.1: Tension force applied to test specimen. Ultimate failure near $2500 \mathrm{lbf}$.

Table 2.1: Tensile specimen dimensions

\begin{tabular}{|l|l|l|l|l|}
\hline $\begin{array}{l}\text { Sample } \\
\#\end{array}$ & $\mathrm{~h}(\mathrm{~mm})$ & $\mathrm{w}(\mathrm{mm})$ & $\mathrm{I}(\mathrm{mm})$ & $\begin{array}{l}\text { Area } \\
\left(\mathrm{mm}^{2}\right)\end{array}$ \\
\hline
\end{tabular}




\begin{tabular}{|r|r|r|r|r|} 
& & & & \\
\hline 6 & 4.6228 & 9.1694 & 135.6614 & 42.388 \\
\hline 7 & 4.699 & 9.1186 & 135.6614 & 42.848 \\
\hline
\end{tabular}

\section{Instron Test Results}

Table 2.2 compiles the experimentally measured elastic modulus and ultimate tensile strengths for samples tested in both the 1-1 and 2-2 directions. These material properties agree well with published data (add references), and are necessary input for subsequent FEA models.

Table 2.2: Results from tensile tests

\begin{tabular}{|c|c|c|c|c|}
\hline $\begin{array}{l}\text { Sample } \\
\#\end{array}$ & Area $\left(\mathrm{mm}^{2}\right)$ & \multicolumn{2}{|l|}{$\begin{array}{l}\text { Failure Load } \\
(\mathrm{N})\end{array}$} & $\begin{array}{l}\mathrm{E} \\
(\mathrm{MPa})\end{array}$ \\
\hline 6 & 42.39 & 10642 & 251.1 & 3638 \\
\hline 7 & 42.85 & 11254 & 262.6 & 5148 \\
\hline
\end{tabular}

\section{Gas Gun Tests}

A gas-propelled gun located at the University of California, Santa Barbara was used to measure the ballistic performance of the glass/polyester armor. The basic components of the gun are shown in Figure 2.

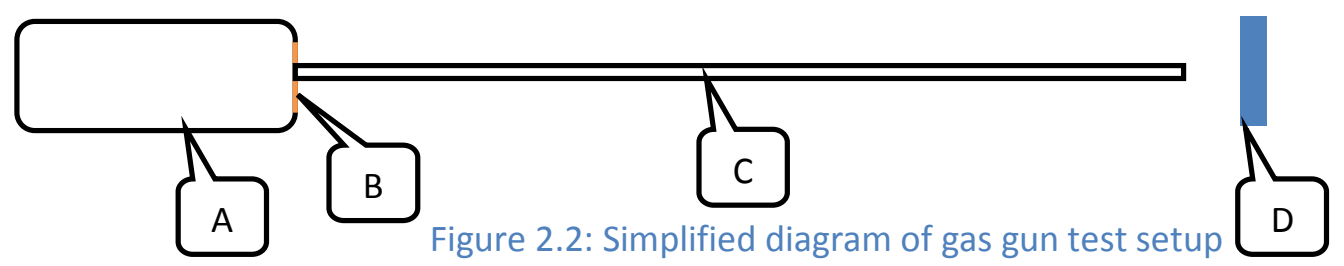

Chamber A is charged with high-pressure gas. Maximum internal pressure is controlled by a thin brass shim bolted across an access hole in the pressure chamber at outlet (B). Brass shims of precise thickness will burst at a tightly controlled range of pressure, providing a mechanical pressure switch for the pressure vessel. When the brass shim bursts it causes a rapid release of the chamber gas into the barrel 
(C). The projectile is placed in the barrel just ahead of the 'burst valve' at B and is forced down the barrel by the expanding gas. Shortly after exiting the barrel, the projectile strikes the test panel at (D).

A photograph of the apparatus is shown in Figure 2., and the associated parts referred to in Figure 2.2: Simplified diagram of gas gun test setup are annotated on the photo.

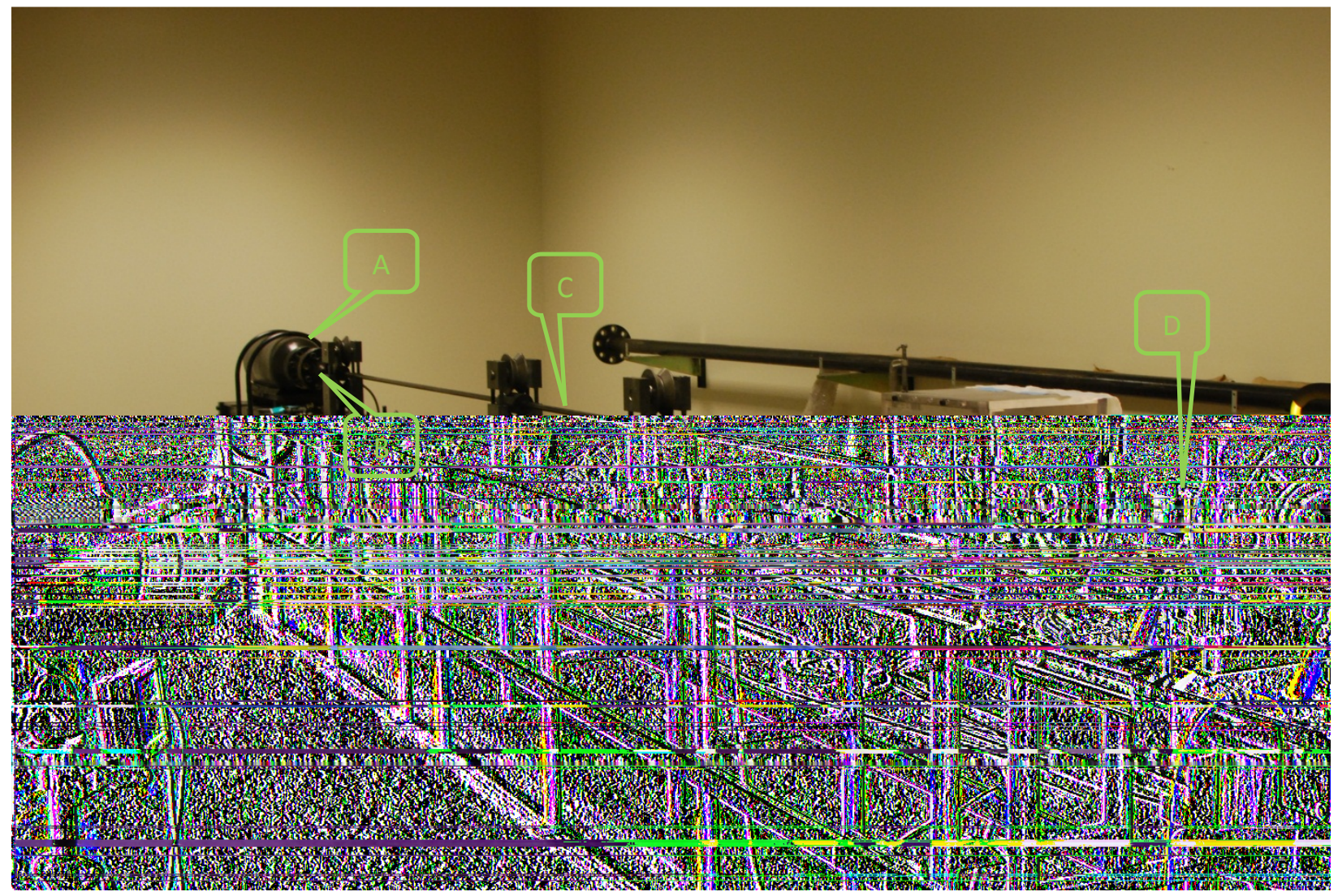

Figure 2.3: Photo of gas gun apparatus used in the testing of fiberglass targets

\section{Fixturing}

Impact test panels were securely held across a 2" by 2" square opening. The Panels are clamped along all edges. Clamping force is provided by steel plates on the top and bottom edges, and by polycarbonate plates on the sides. The clamping force is applied by tightening 4 bolts at each corner of the fixture. A Computer Aided Drawing (CAD) of the fixture is shown in Figure 2.4. 


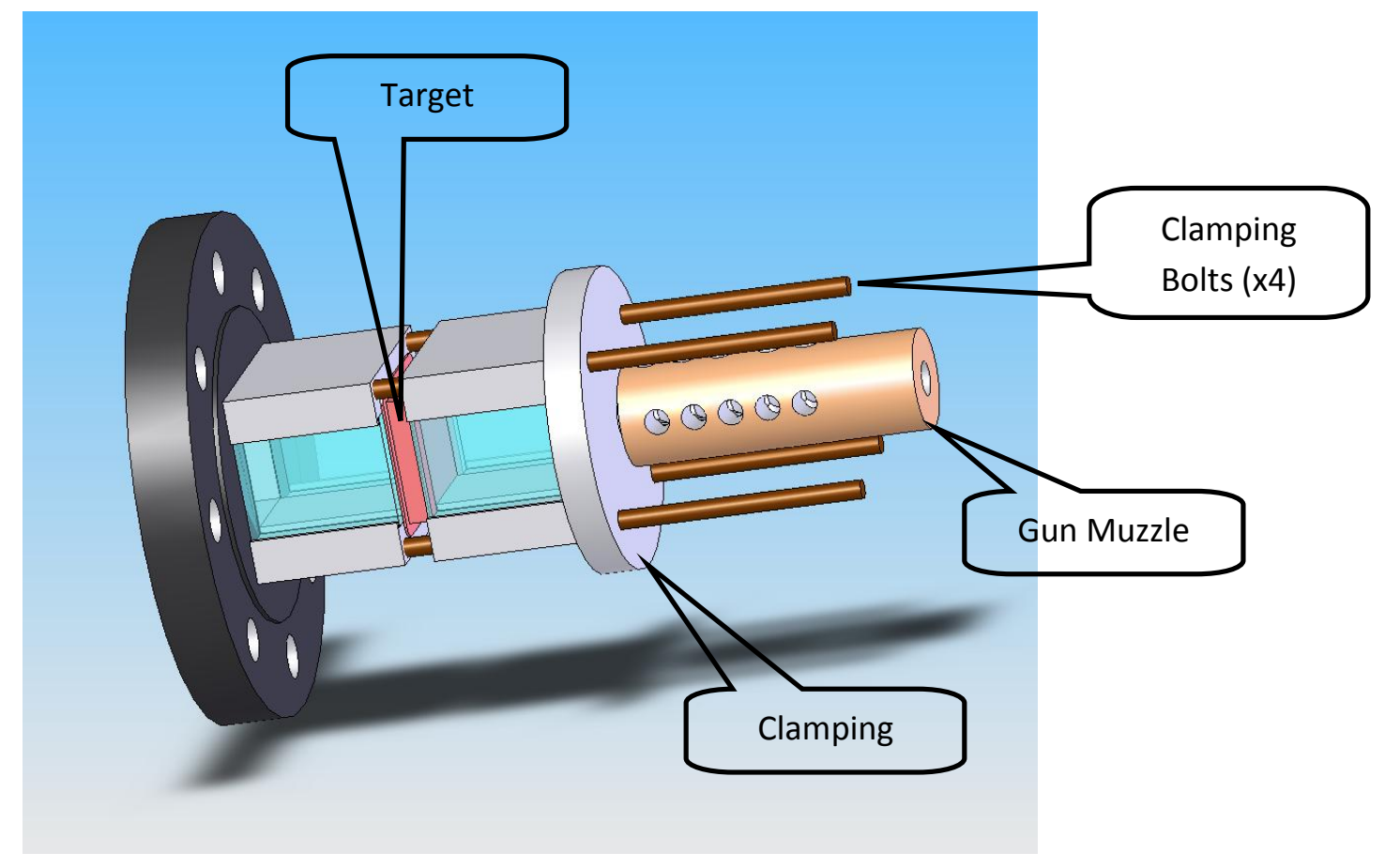

Figure 2.4: Clamping fixture used to hold targets for the gas gun. The target is represented in the model by the pink plate. Note that the cross-drilled gun muzzle is a separate part. CAD model courtesy of UCSB Materials Engineering Department.

Nuts on the four clamping bolts are securely tightened against a clamping plate that holds the target in place. A photo of the test fixture is shown in Figure 2. below. In this photo the gun muzzle has been backed away, and the clamping plate has been removed for clarity. In the photo, the fixture has been slid open, ready to accept another target. From this, one can see why the clamping fixture is comprised of both stainless steel and polycarbonate: the polycarbonate creates an observation window for highspeed recording of the impact event. 


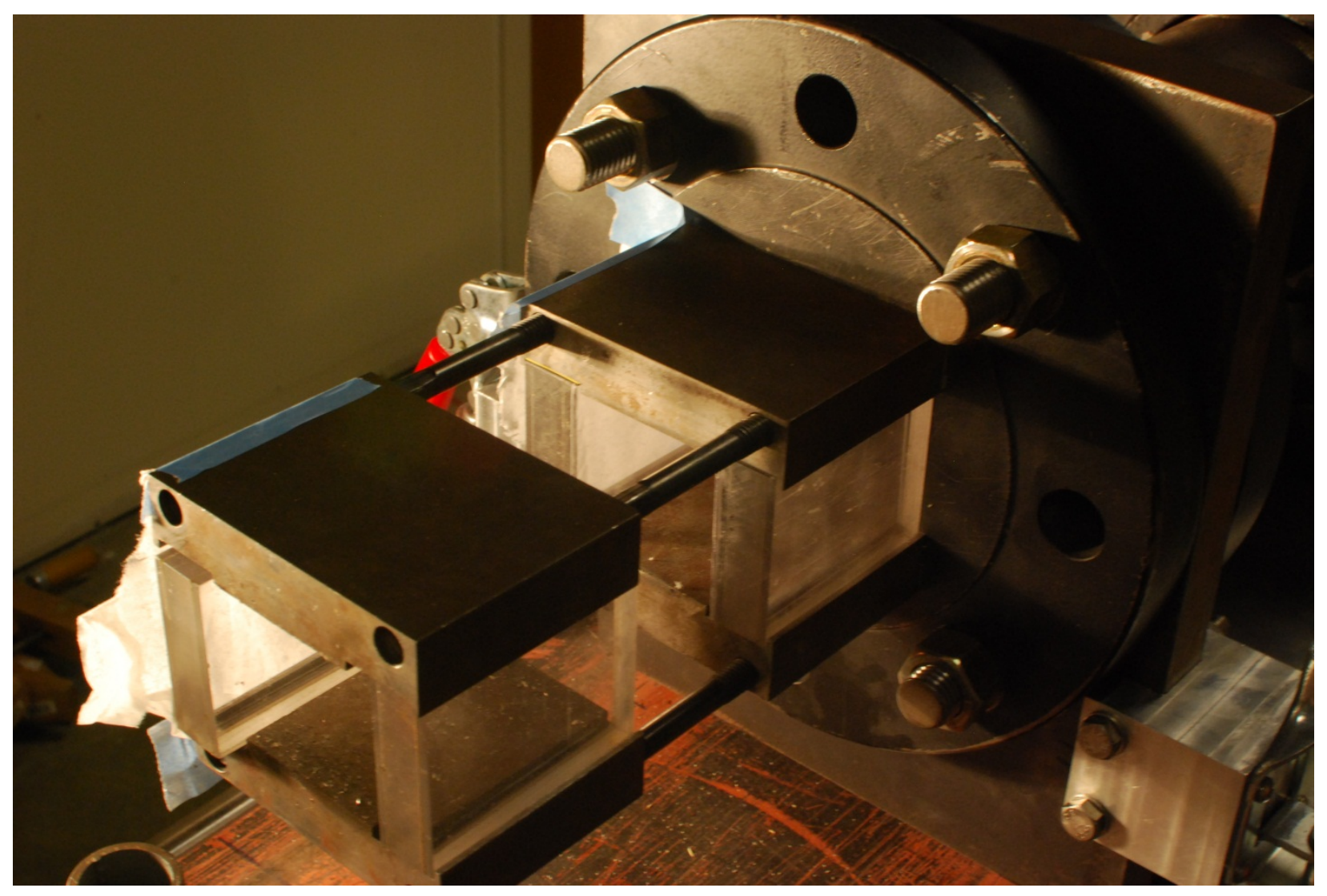

Figure 2.5: Clamping fixture used to hold targets for the gas gun

\section{Sample Manufacturing}

In order to span the 2 " by 2 " test section and allow for secure clamping, test samples were fabricated as squares measuring $2.6 \pm 0.1^{\prime \prime}$ by $2.6 \pm 0.1^{\prime \prime}$ and $0.444^{\prime \prime}$ thick. Specimens were cut using a tile saw with a diamond-tip blade. The tile saw was found to provide a smoother cut than a vertical bandsaw. A CAD model of the test sample is shown below. A fully dimensioned drawing of a test target is included in the Appendix. 


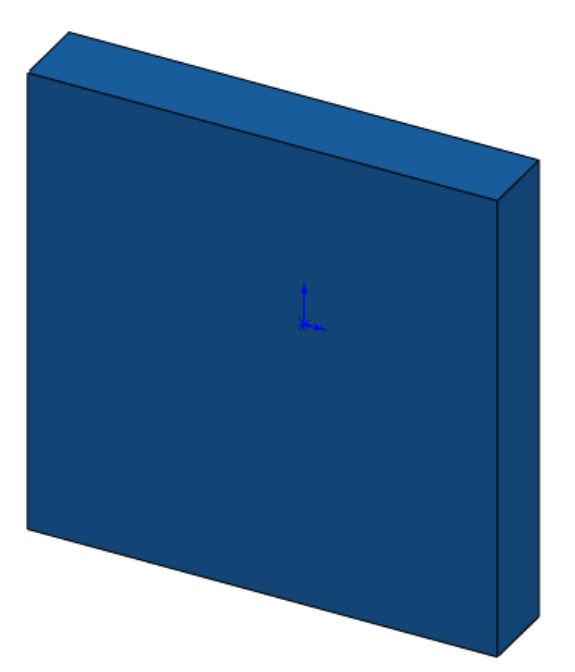

Figure 2.6: CAD model of target plate

\section{Projectile}

Hardened type 304 stainless steel spheres measuring 0.299 inches in diameter were used for all ballistic impact tests. The spheres were purchased from Salem Specialty Ball. This hardened steel is much less susceptible to deformation upon impact than the lead projectiles common among bullets. We found that the typical modeling parameters for type 304 stainless steel were not appropriate for this hardened alloy. The parameters we used are outlined in the modeling section.

The barrel is .30 caliber and, with a $0.299 "$ projectile, the balls would roll freely down the barrel if they were unconstrained. Additionally, the hard steel does not deform to provide a good seal with the barrel to prevent gas blow-by. In order to prevent both these effects, the projectiles are backed with a foam obturator. The obturator is joined to the projectile by wrapping both the obrturator and projectile with scotch tape. A diagram of this assembly is shown below. 


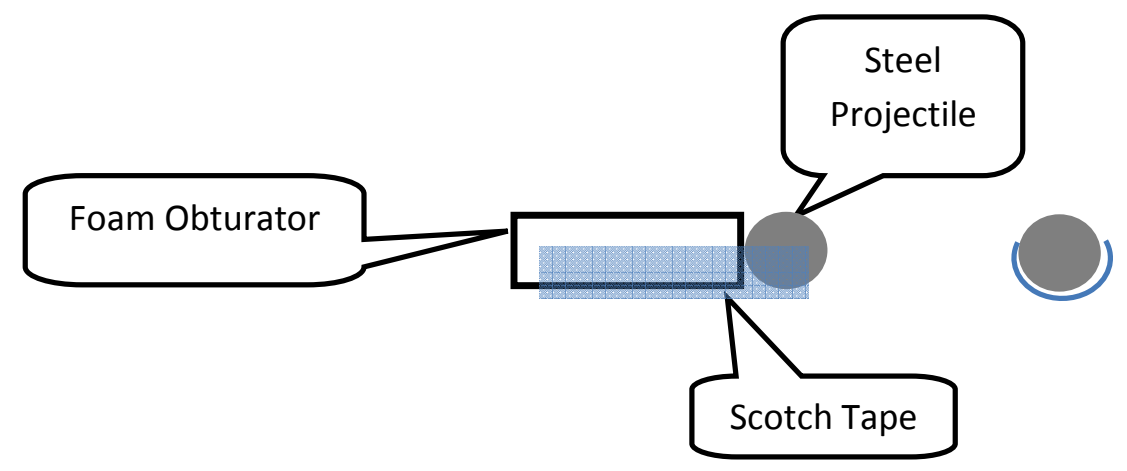

Figure 2.7: Projectile assembly, as inserted in the breach of the gas gun

\section{Gas Propellant Choice}

Two types of gases were used to propel the projectile, nitrogen and helium. When using a nitrogen gas we found the velocity was limited to a maximum of approximately 450 meters per $\mathrm{sec}(\mathrm{m} / \mathrm{s})$. After this velocity, projectile speed did not increase with increasing charge pressure. This is due to choking of the flow as the nitrogen reaches Mach 1. To achieve higher impact velocities, a gas with a higher wave speed (and thus an increased velocity at Mach 1) was needed. Helium is less dense than nitrogen, and was able to provide the velocities required to find the ballistic limit of the panels. Hydrogen could reach even higher velocities than helium but carries additional flammability risks. In the present set of tests, helium was sufficient to achieve the velocities needed to find the V50 of the targets.

\section{Instrumentation}

Impact velocity was measured in two ways. For all shots, impact velocity was measured using a highspeed camera, while for some shots, this data was verified with laser gates at the exit of the barrel. The gates detect the passing of the ball as it interrupts the laser beam. The distance between the lasers is known, which then allows for the calculation of velocity. In the event of penetration, the exit velocity of the projectile is measured using the high-speed camera. This is accomplished by using a calibration ruler 
along the projectile exit trajectory, as shown below. The ruler is placed in the center of the test section, in the flight path of the projectile, enabling a simple measurement of projectile position .

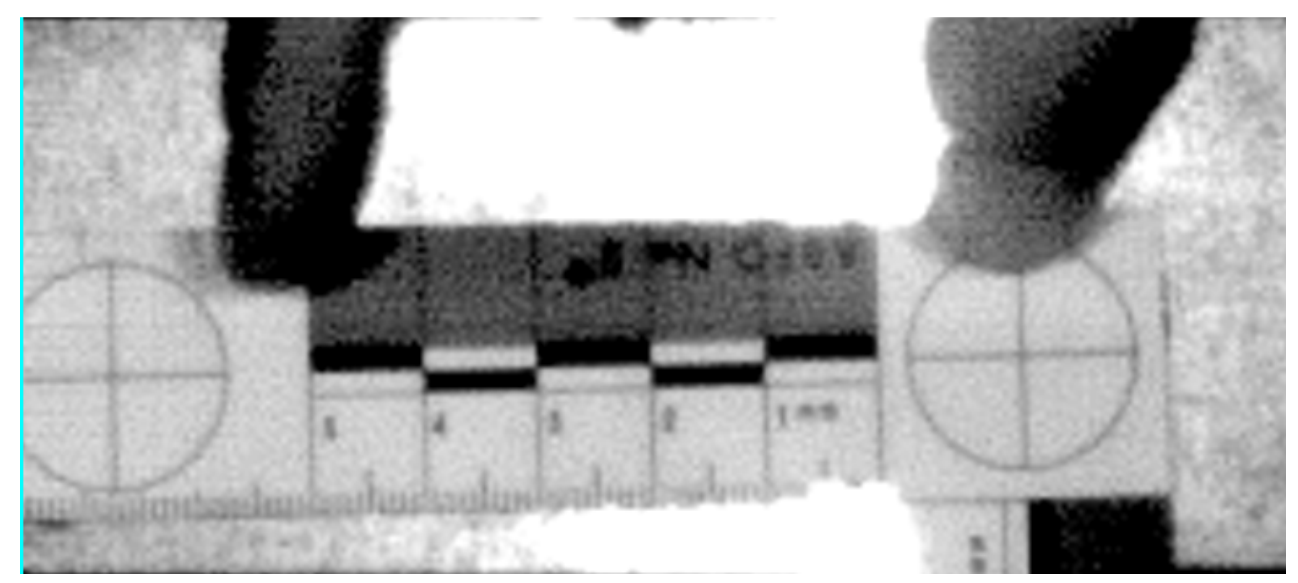

Figure 2.8: Ruler used to calibrate distance as viewed by the high-speed camera

Next, the position of the projectile is measured in each frame. The time between frames is known, since the frame-rate is set by the user. This allows for a plot to be made showing position on the $y$-axis and time on the x-axis as shown below. Each point represents the position of the projectile at one frame of the video. Velocity of the projectile is assumed to be constant over the approximately 4" flight span from the end of the barrel until impact with the target. As shown in Figure 2.9 below, the position varies linearly with time. Naturally, the velocity is the slope of this line. 


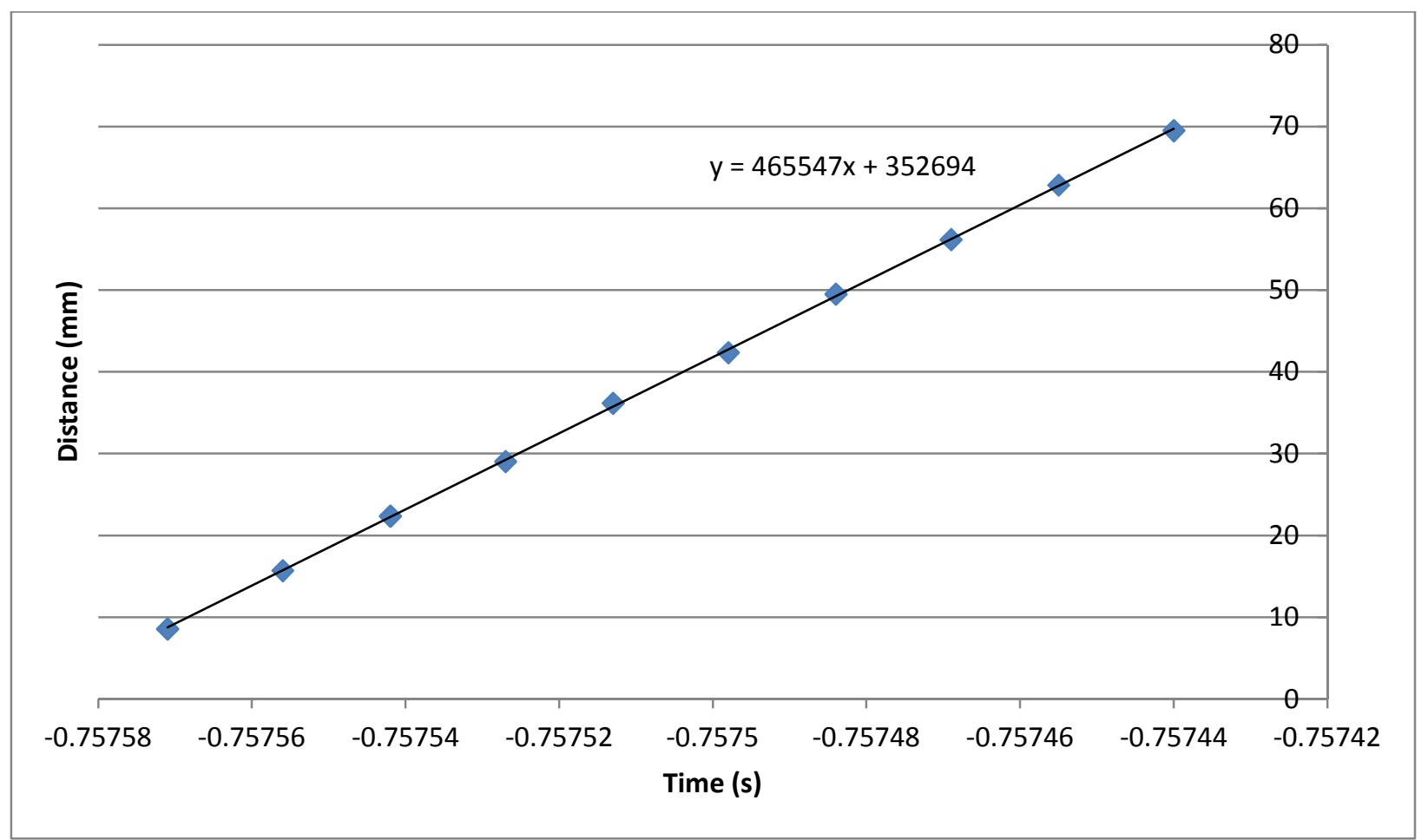

Figure 2.9: Plot used to determine velocity of Shot \#1

This measurement is akin to taking the time derivative of the projectile's position over a span of approximately $60 \mathrm{~mm}$ between the exit of the barrel and the impact face of the target plate. This method averages the position/time derivative over all data points taken, improving accuracy over simply measuring the difference between any two points. Increasing frame rate requires compromises, such as reducing frame size, decreasing resolution, or increasing the amount of available backlighting.

In Figure 2., the value for the slope of the line is presented in $\mathrm{mm} / \mathrm{sec}$. This means that in the case shown above for shot \#1 that the velocity of the projectile was approximately $465 \mathrm{~m} / \mathrm{s}$ immediately before impact. All other shots had velocity measured in the same manner. No shots showed any significant variation from the linear pattern in Figure 2., and all shots that had velocities measured by 
laser and by video showed good agreement (less than $1 \%$ difference) between the two methods. This is shown in Table 2.3, below, for all shots on which the laser method was used.

Table 2.3: Comparison of laser and videographical velocity measurements

\begin{tabular}{|c|c|c|c|}
\hline Shot \# & Impact Vel. m/s (Camera) & $\begin{array}{l}\text { Impact Vel. m/s } \\
\text { (Laser) }\end{array}$ & \% Difference \\
\hline 9 & 548 & 550 & -0.0036 \\
\hline 11 & 552 & 550 & 0.0036 \\
\hline 12 & 555 & 559 & -0.0072 \\
\hline
\end{tabular}

\section{Velocity Adjustment}

The gun utilized in this test has no setting to guarantee a particular exit velocity, however several parameters can be adjusted to change the velocity in a predictable manner. By increasing the thickness of the brass shim, the burst pressure of the tank is higher, thus increasing the velocity. This is a coarse adjustment. Finer adjustments can be made by changing the position of the projectile in the barrel. By placing the projectile farther down the 17 foot long barrel, the projectile has less distance in which to accelerate due to the pressure difference created in the gun barrel, thus reducing impact velocity. Due to variation in how well each individual projectile seals to the barrel, velocity can only be predicted to about $\pm 30 \mathrm{~m} / \mathrm{s}$ with the setup used.

\section{Gas Gun Test Procedure}

The procedure for finding the ballistic limit of the panels was based upon MIL-STD-662F [9], the Department of Defense test standard for finding the V50 ballistic limit of armor. An impact velocity was chosen arbitrarily for the first shot. According to MIL-STD-662F [9] the first shot should be taken at the expected impact velocity. In this case, since the armor is not being certified to protect against a particular round, there was no expected impact velocity for the first shot, so the velocity was chosen based on related experience of staff at the test facility, with the intent that the velocity of the first shot 
be reasonably close to an estimate of the V50. After the first shot, the test panel is checked for penetration. If penetration occurs, velocity for the subsequent shot is decreased. If no penetration is observed, velocity for the next shot is increased. Reference [9] provides guidelines for this practice, if the impact velocity of each shot is precisely adjustable. By taking several shots and adjusting velocity, the tester can eventually arrive at a close approximation of the ballistic limit. A new projectile, test panel, and brass shim are used for each shot.

\section{Experimental Results: Gas Gun Tests}

\section{V50}

Ballistic penetration experiments were conducted on samples of fiberglass armor to determine the velocity for which $50 \%$ of the projectiles would fully penetrate the armor (commonly referred to as the V50). A total of 12 shots were taken at identical targets, each cut from the same armor panel. The impact velocities for each shot are shown in Table .1 below.

\section{Table 3.1 Impact Velocity of Gas Gun Shots}

\begin{tabular}{|r|r|}
\hline \multicolumn{1}{|l|}{ Shot \# } & Impact Vel. m/s (Camera) \\
\hline 1 & 465 \\
\hline 2 & 435 \\
\hline 3 & 569 \\
\hline 4 & 550 \\
\hline 5 & 618 \\
\hline 6 & 566 \\
\hline 7 & 576 \\
\hline 8 & 549 \\
\hline 9 & 548 \\
\hline 10 & 579 \\
\hline 11 & 552 \\
\hline 12 & 555 \\
\hline
\end{tabular}


A plot of the exit velocity against impact velocity, Figure 3.1, illustrates the method for determining the V50 of the subject armor. Figure 3.1 also shows how the exit velocity changes with impact velocity, and makes clear that $50 \%$ of the total shots at impact velocities less than $560 \mathrm{~m} / \mathrm{s}$ did not penetrate the target, while $50 \%$ of those above $560 \mathrm{~m} / \mathrm{s}$ did fully penetrate the target. These data were used to assign a V50 of approximately $560 \mathrm{~m} / \mathrm{s}$, with an estimated error margin of about $\pm 5 \mathrm{~m} / \mathrm{s}$.

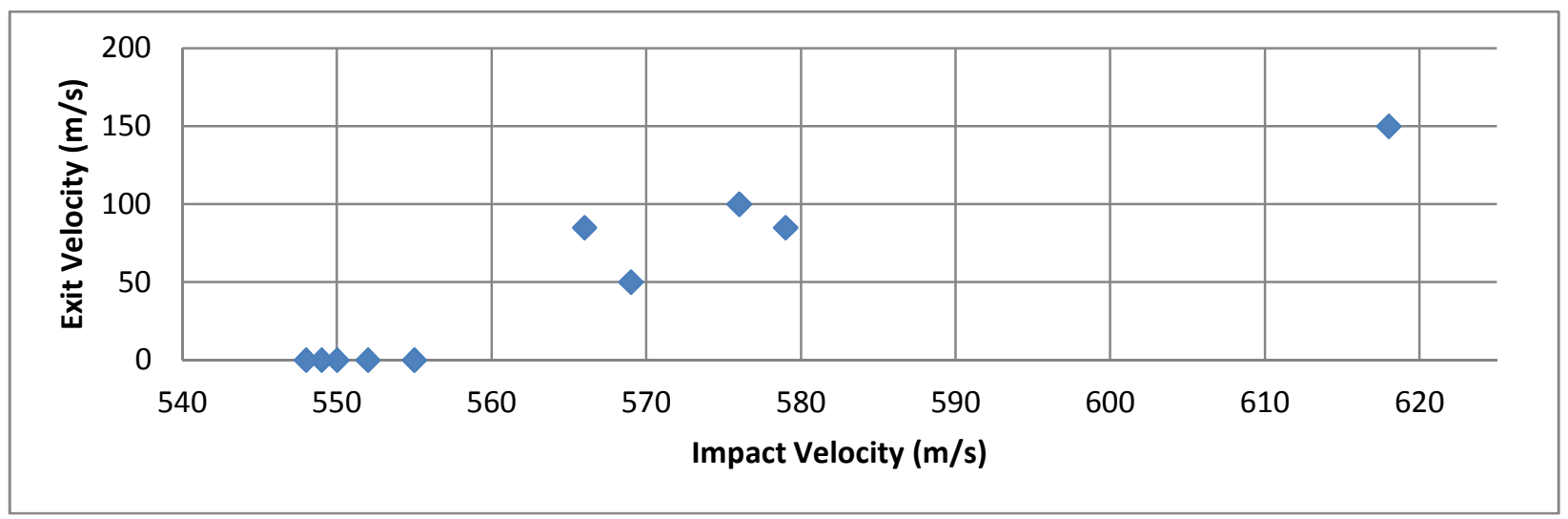

Figure 3.1: Impact tests over a range of velocities were used to determine the V50 for a fiberglass armor system. These tests also show that, following complete penetration, the exit velocity increases with increasing impact velocity.

The data contained in Figure 3.1 show that the largest impact velocity that did not completely penetrate was $555 \mathrm{~m} / \mathrm{s}$. No shot slower than this velocity penetrated the plate. The slowest velocity that penetrated the plate was $566 \mathrm{~m} / \mathrm{s}$. No shot faster than $566 \mathrm{~m} / \mathrm{s}$ failed to penetrate the plate. Therefore, it is likely that V50 is roughly $560 \mathrm{~m} / \mathrm{s}$. These observations, combined with the fact that exit velocity tends to increase with increasing impact velocity show fairly consistent results. If several shots were taken at similar velocities, and produced dramatically different results, then it would suggest that there may have been a problem with the test setup.

According to [10] one way to estimate V50 from shots which did penetrate the target is to calculate the kinetic energy of the projectile before impacting and after exiting the plate. By finding the change in 
kinetic energy, a velocity can be calculated that would just bring the projectile to a zero velocity. This calculation is intended only as an estimation that can be used to narrow down to the appropriate V50. A sample calculation for this procedure can be found in the appendix. By averaging the results of this procedure for all shots which penetrated the plates, the estimate for V50 is found to be $565 \mathrm{~m} / \mathrm{s}$. Since this is in close agreement (error $<1 \%$ ) with the earlier estimate of $560 \mathrm{~m} / \mathrm{s}$, it supports our experimentally measured value of $\mathrm{V} 50=560 \mathrm{~m} / \mathrm{s}$.

\section{Penetration Depth}

Whenever a projectile did not pass through the target, we measured the depth of penetration for that projectile. For purposes of this study, penetration depth is measured from the plane formed by the undeformed incident surface on the target to the front of the arrested projectile in the target. This result provides an additional experimental measurement with which to tune and adjust the FEA model. Once the model was tuned to accurately reproduce the V50 of the plate, it was checked by observing the depth to which simulated shots below the V50 penetrate the plate. Whenever a projectile was defeated, the penetration depth was measured on sectioned samples of armor using a bandsaw to cut a cross section through the centerline of the target. Summary data is shown in Table 3.2, below.

Table 3.2: Embedded Depth of Projectiles that Partially Penetrated the Target

\begin{tabular}{|c|c|c|}
\hline Shot \# & $\begin{array}{c}\text { Impact } \\
\text { Velocity (m/s) }\end{array}$ & $\begin{array}{c}\text { Penetration } \\
\text { Depth (inches) }\end{array}$ \\
\hline 1 & 465 & 0.423 \\
\hline 2 & 435 & 0.369 \\
\hline 4 & 550 & 0.582 \\
\hline 8 & 549 & 0.587 \\
\hline 9 & 548 & 0.574 \\
\hline 11 & 552 & 0.568 \\
\hline 12 & 555 & 0.604 \\
\hline
\end{tabular}


Figure 3.2 plots these data, showing a linear relationship between penetration depth and impact velocity.

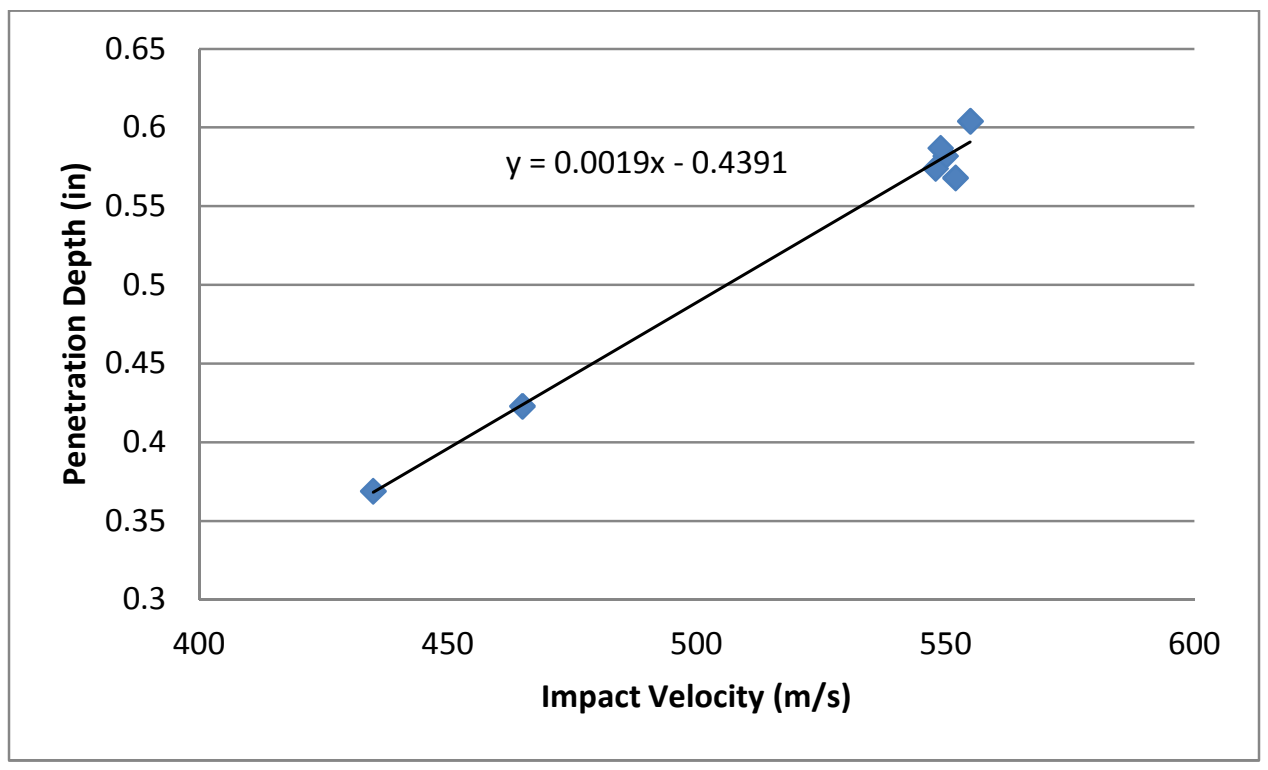

Figure 3.2: Penetration depth as a function of impact velocity for projectiles captured in the target.

It should be noted that although kinetic energy varies with the square of velocity, the penetration depth seems to vary linearly over the test range of 435 to $555 \mathrm{~m} / \mathrm{s}$. The cluster of shots near $550 \mathrm{~m} / \mathrm{s}$ is a result of the experimental process by which we narrowed in on V50. The narrow distribution of penetration depth near V50 suggests that these measurements are reasonably accurate and that the experimental approach to finding V50 produced consistent results. Additionally, it is important to note that the penetration depth, in many cases, is greater than the initial $0.444^{\prime \prime}$ thickness of the plate. This is due to the extensive damage zones that create 'blossoming' deformation in the plate. During the impact event, ply delamination as well as fiber failure and debonding change the local density of the composite, resulting in large dilatation. The end result is an apparent increase in plate thickness that provides a larger distance to arrest the projectile. 


\section{Model Development}

Ballistic penetration was modeled using LSDYNA, a commercially available dynamic finite element package. In both the experiment and modeling, the user must input the geometry and properties of both the projectile and the target. In the present case, the projectile was a $7.59 \mathrm{~mm}$ diameter 304 stainless steel spherical ball while the target was a square, thru-thickness section of glass/polyester armor. The following sections detail the material models used for the finite element simulations. Two models were developed in LSDYNA. Both models used the same material model for the projectile, but a different material model for the target plate, both of which were derived from libraries available in the LSDYNA package.

\section{Projectile Modeling: Material Type 15}

Material type 15 is based on a Johnson-Cook viscoplastic model. [11]. This model expresses the stress in the material as a function of strain, strain rate, and temperature. The Johnson-Cook expression for stress is given by:

$$
\sigma=\left[A+B \varepsilon^{n}\right]\left[1+C \ln \dot{\varepsilon}^{*}\right]\left[1-T^{* m}\right]
$$

In this model, the values for A, B, C, n, and $m$ may be varied to fit the specific material. The values of these parameters are chosen by applying curve fits to test data taken at several elevated strain rates. There have been numerous studies that support the effectiveness of the Johnson-Cook model when used with metals, including [12], [13], [14]. The model parameters used for the type 304 SS are shown in the Table 4.1, below. These parameters were determined by our collaborators at UCSB. [15]. 
Table 4.1: Johnson-Cook Parameters for Steel used in the FEA Models

\begin{tabular}{|c|c|c|}
\hline & Projectile & Typical 304 SS \\
\hline Density, $\rho(\mathrm{kg} / \mathrm{m} 3)$ & 7920 & 7920 \\
\hline Poisson's Ratio, $v$ & 0.29 & 0.29 \\
\hline Young's Modulus, $\mathrm{E}(\mathrm{GPa})$ & 200 & 200 \\
\hline $\mathrm{A}(\mathrm{MPa})$ & 1100 & 260 \\
\hline $\mathrm{B}(\mathrm{MPa})$ & 610 & 1350 \\
\hline $\mathrm{n}$ & 0.4 & 0.62 \\
\hline $\mathrm{m}$ & 0.82 & 1.0 \\
\hline $\mathrm{C}$ & 0.013 & 0.02 \\
\hline$\dot{\varepsilon}_{0}$ & 1.0 & 1.0 \\
\hline $\mathrm{T}_{\mathrm{m}}(\mathrm{K})$ & 1800 & 1800 \\
\hline $\mathrm{T}_{0}(\mathrm{~K})$ & 300 & 300 \\
\hline $\mathrm{c}_{\mathrm{p}}(\mathrm{J} / \mathrm{kg} \mathrm{K})$ & 450 & 450 \\
\hline & & \\
\hline
\end{tabular}

These parameters are slightly different from the typical constants used for type 304 SS (rightmost column in Table 4.1), due, in part, to the hardening of the projectiles used in our experiments.

In addition to the Johnson-Cook constitutive equation, an Equation of State (EOS) was required to deal with dilatation of the solid (or brick) elements used in this model. The EOS models the response of the material elements to the dilatational stresses (terms on the diagonal of the stress tensor) rather than the deviatoric components, which are contained in the constitutive equation [16]. For shell elements, the EOS may be overlooked, due to their lack of volume. The two most common formulations for the EOS of metals are piecewise-linear and the Mie-Gruneisen [11]. Established parameters for the Gruneisen equation for type 304 stainless steel were found in [16] and are listed in Table 4.2, below.

Table 4.2: Gruneisen parameters used to the 304 equation of state.

\begin{tabular}{|c|c|c|c|c|c|c|c|}
\hline $\mathrm{C}$ & $\mathrm{S} 1$ & $\mathrm{~S} 2$ & $\mathrm{~S} 3$ & $\gamma 0$ & $\mathrm{~A}$ & $\mathrm{E} 0$ & $\mathrm{~V} 0$ \\
\hline $4570 \mathrm{~m} / \mathrm{s}$ & 1.49 & 0 & 0 & 1.93 & 0.5 & $\begin{array}{c}1.048^{*} 10^{9} \\
\mathrm{~J} / \mathrm{m}^{3}\end{array}$ & 1 \\
\hline
\end{tabular}

Details of the Gruneisen equation can be found in [16]. 


\section{Target Modeling: Material Type 3}

Initial impact modeling was conducted using Material type 3 in LSDYNA. This material type was chosen for simplicity and the built-in rate dependence. Material type 3 is referred to in LSDYNA as 'PlasticKinematic'. This material has an obvious shortfall for modeling composites as it does not take orthotropic material properties into account. However, it was used as a first approximation to establish a baseline 'learning curve' for our initial simulations. Due to the out-of-plane load case, it was felt that tuning with this model could possibly provide useful results and experience with tuning parameters. The simplicity of this model type makes it easier to tune, and also easier to compare the tuned model to estimates for material properties gathered from Instron testing.

An additional benefit to material type 3 is that there is a built-in strain rate dependence. The formulation for strain rate dependence used in material type 3 is that proposed by Cowper and Symonds. This formulation changes the yield stress of the material as strain rate changes. [17]. However, this may be of limited use for the glass fiber reinforced plastics (GFRP) used in our experiments. While the polyester matrix exhibits some plasticity, the glass fibers fail in a brittle manner, without passing through a yielding point and plastic deformation. Even so, the complexities of delamination, fiber debonding and subsequent pull-out, lend a degree of 'synthetic plasticity' that can be captured, phenomenologicaly, through a plasticity model.

The final benefit to material type 3 is its computational simplicity compared with more complicated composite damage models. The guiding idea behind this approach was, if useful results could be obtained with this simple model, then it may be a better option for obtaining a first estimate of ballistic limit than more complex models in similar load cases.

Input parameters for the target plate using material type 3 are shown in Table 4.3, below. These properties were determined from published values for GFRP in [18] as well as properties extracted from 
the quasi-static tests presented earlier. A schematic representation of the stress-strain response is shown in Figure 4.1

Table 4.3: Untuned FEA Modeling Parameters for GFRP using Material Type 3

\begin{tabular}{|c|c|c|c|c|c|c|}
\hline Variable & $\begin{array}{c}\text { Density } \\
\left(\mathrm{kg} / \mathrm{m}^{3}\right)\end{array}$ & $\begin{array}{c}\text { Elastic } \\
\text { Modulus } \\
(\mathrm{Pa})\end{array}$ & $\begin{array}{c}\text { Poisson's } \\
\text { Ratio }\end{array}$ & $\begin{array}{c}\text { Yield Stress } \\
(\mathrm{Pa})\end{array}$ & $\begin{array}{c}\text { Tangent } \\
\text { Modulus } \\
(\mathrm{Pa})\end{array}$ & $\begin{array}{c}\text { Hardening } \\
\text { Parameter, } \\
\beta\end{array}$ \\
\hline Value & 1950 & $1.3 * 10^{10}$ & 0.284 & $2.35 * 10^{9}$ & - & 1.0 \\
\hline
\end{tabular}

\begin{tabular}{|c|c|c|c|c|c|}
\hline Variable & $\begin{array}{c}\text { Cowper- } \\
\text { Symonds C }\end{array}$ & $\begin{array}{c}\text { Cowper- } \\
\text { Symonds P }\end{array}$ & Failure Strain & $\begin{array}{c}\text { Viscoplastic } \\
\text { Formula Flag }\end{array}$ & \\
\hline Value & 1520 & 13.43 & 0.02 & 1 & \\
\hline
\end{tabular}

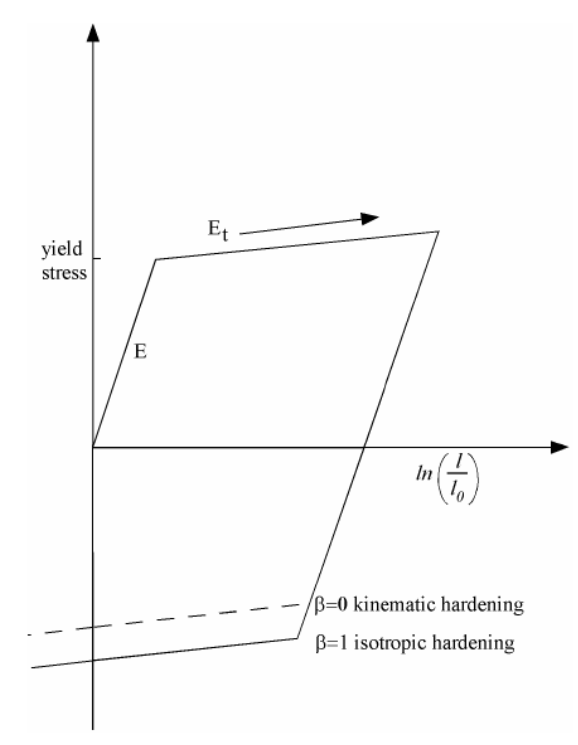

Figure 4.1: Schematic stress-strain response courtesy of the LSDYNA Keyword Manual demonstrating the Tangent Modulus (Et) and Hardening Parameter $(\beta)$. The hardening parameter value may be adjusted to any value between 0 and 1 . 


\section{Composite Damage Model: Material Type 59}

Material type 59 in LSDYNA is intended to capture the damage in composite materials. This model is based upon the damage model described by Cheng and Hallquist [19] and incorporates 8 failure modes, which are:

- Mode1: Tensile longitudinal (material 1 direction) fiber failure

- Mode2: Transverse (material 2 direction) tensile failure

- Mode 3: Through-thickness (material 3 direction) shear (combined with longitudinal tension)

- Mode 4: Delamination

- Mode 5: Through-thickness shear (combined with transverse tension)

- Mode 6: Longitudinal compressive failure of the fibers

- Mode 7: Transverse compression

- Mode 8: Through-thickness compression

Complete formulas for this model can be found in Appendix B.

An in-depth explanation of these failure criteria is available in [19] while an explanation of how these extra variables are stored in LSDYNA can be found in [20]. This material type does not take strain rate effects into account. However, for the relatively narrow range of impact speeds tested in these experiments, the model can be tuned for properties over this specific speed range. It is possible that rate effects may play a larger role as the projectile slows inside the target. When type 59 is used with solid elements, as it was in this case, this model can check for delamination effects by observing matrix failure in the through-thickness $\left.{ }_{33}\right)$ direction. [11]. Other laminate failure criteria are available in LSDYNA, such as that suggested by Tsai and $\mathrm{Wu}$, but these criteria were only available for shell elements. Type 59 with solid elements was chosen for its ability to simulate delamination, which 
according to the armor manufacturer, is the principal mechanism responsible for the total energy absorbed by the target. [21].

This model is more computationally expensive to run than material type 3 , but has the advantage of incorporating orthotropic properties. Furthermore, the fiber directions are established, and fiber failure properties are different in compression and tension. [22].

Initial properties for this model were based on Instron testing, as well as properties developed in [6], [7], and [8]. These properties are shown in the Table 4.4, below. Note that some parameters are unused.

Table 4.4: Type 59 model properties. In this model, the first two rows define material moduli, the variables AOPT, MACF, and the 3rd and 4th rows define the material primary axes. The 5 th row defines material failure parameters.

\begin{tabular}{|c|c|c|c|c|c|c|c|}
\hline Variable & $\begin{array}{c}\text { Density } \\
\left(\mathrm{kg} / \mathrm{m}^{3}\right)\end{array}$ & $\begin{array}{c}\text { Elastic } \\
\text { Modulus } \\
(\mathrm{Pa})\end{array}$ & $\begin{array}{c}\text { Elastic } \\
\text { Modulus }_{b} \\
(\mathrm{~Pa})\end{array}$ & $\begin{array}{c}\text { Elastic } \\
\text { Modulus }_{\mathrm{c}} \\
(\mathrm{Pa})\end{array}$ & $\begin{array}{c}\text { Poisson's } \\
\text { Ratio }_{\mathrm{ba}}\end{array}$ & $\begin{array}{c}\text { Poisson's } \\
\text { Ratio }_{\mathrm{ca}}\end{array}$ & $\begin{array}{c}\text { Poisson's } \\
\text { Ratio }_{\mathrm{cb}}\end{array}$ \\
\hline Value & 1950 & $1.3^{*} 10^{10}$ & $1.3 * 10^{10}$ & $3.5^{*} 10^{9}$ & 0.38 & 0.057 & 0.057 \\
\hline
\end{tabular}

\begin{tabular}{|c|c|c|c|c|c|c|}
\hline Variable & $\mathrm{G}_{\mathrm{ab}}(\mathrm{Pa})$ & $\mathrm{Gbc}(\mathrm{Pa})$ & $\mathrm{Gca}(\mathrm{Pa})$ & Kfail & AOPT & MACF \\
\hline Value & $4.0 * 10^{9}$ & $4.0^{*} 10^{9}$ & $4.0^{*} 10^{9}$ & $2.23^{*} 10^{10}$ & 2 & 1 \\
\hline
\end{tabular}

\begin{tabular}{|c|c|c|c|c|c|c|}
\hline Variable & $\mathrm{XP}$ & $\mathrm{YP}$ & $\mathrm{ZP}$ & $\mathrm{A} 1$ & $\mathrm{~A} 2$ & $\mathrm{~A} 3$ \\
\hline Value & - & - & - & 1 & 0 & 0 \\
\hline
\end{tabular}

\begin{tabular}{|c|c|c|c|c|c|c|}
\hline Variable & V1 & V2 & V3 & D1 & D2 & D3 \\
\hline Value & - & - & - & 0 & 0 & 1 \\
\hline
\end{tabular}

\begin{tabular}{|c|c|c|c|c|c|c|c|c|}
\hline Variable & $\begin{array}{c}\text { Shear } \\
\text { Strength } \\
(\mathrm{Pa})\end{array}$ & $\begin{array}{c}\text { Longitudinal } \\
\text { Tensile } \\
\text { Strength }_{\mathrm{a}} \\
(\mathrm{Pa})\end{array}$ & $\begin{array}{c}\text { Transverse } \\
\text { Tensile } \\
\text { Strength } \\
(\mathrm{Pa})\end{array}$ & $\begin{array}{c}\text { Transverse } \\
\text { Compressive } \\
\text { Strength } \\
(\mathrm{Pa})\end{array}$ & $\begin{array}{c}\text { Non- } \\
\text { Linear } \\
\text { Shear } \\
\alpha\end{array}$ & $\begin{array}{c}\text { Normal } \\
\text { Tensile } \\
\text { Strength } \\
(\mathrm{Pa})\end{array}$ & $\begin{array}{c}\text { Shear } \\
\text { Strength }\end{array}$ & $\begin{array}{c}\text { Shear } \\
\text { Strength }_{\mathrm{Zx}}\end{array}$ \\
\hline Value & $7.5^{*} 10^{7}$ & $4.3^{*} 10^{8}$ & $6.9^{*} 10^{7}$ & $6.9^{*} 10^{8}$ & 0 & $6.0^{*} 10^{7}$ & $7.5^{*} 10^{7}$ & $7.5^{*} 10^{7}$ \\
\hline
\end{tabular}




\section{Meshing in TrueGrid}

The preprocessor TrueGrid was used to generate the mesh for both the impacting projectile and the target, Figure 5.1. The target measures 2 inches by 2 inches by 0.444 thick, and all nodes at the edge boundaries have zero displacement and rotation, corresponding to fixed boundary conditions. In the experiments the sample was firmly clamped at the edges, approximating fixed boundary conditions. The sphere is meshed as a separate solid, positioned immediately above the center of the target. The mesh for the sphere was generated by Dr. Tom Mase at Cal Poly.

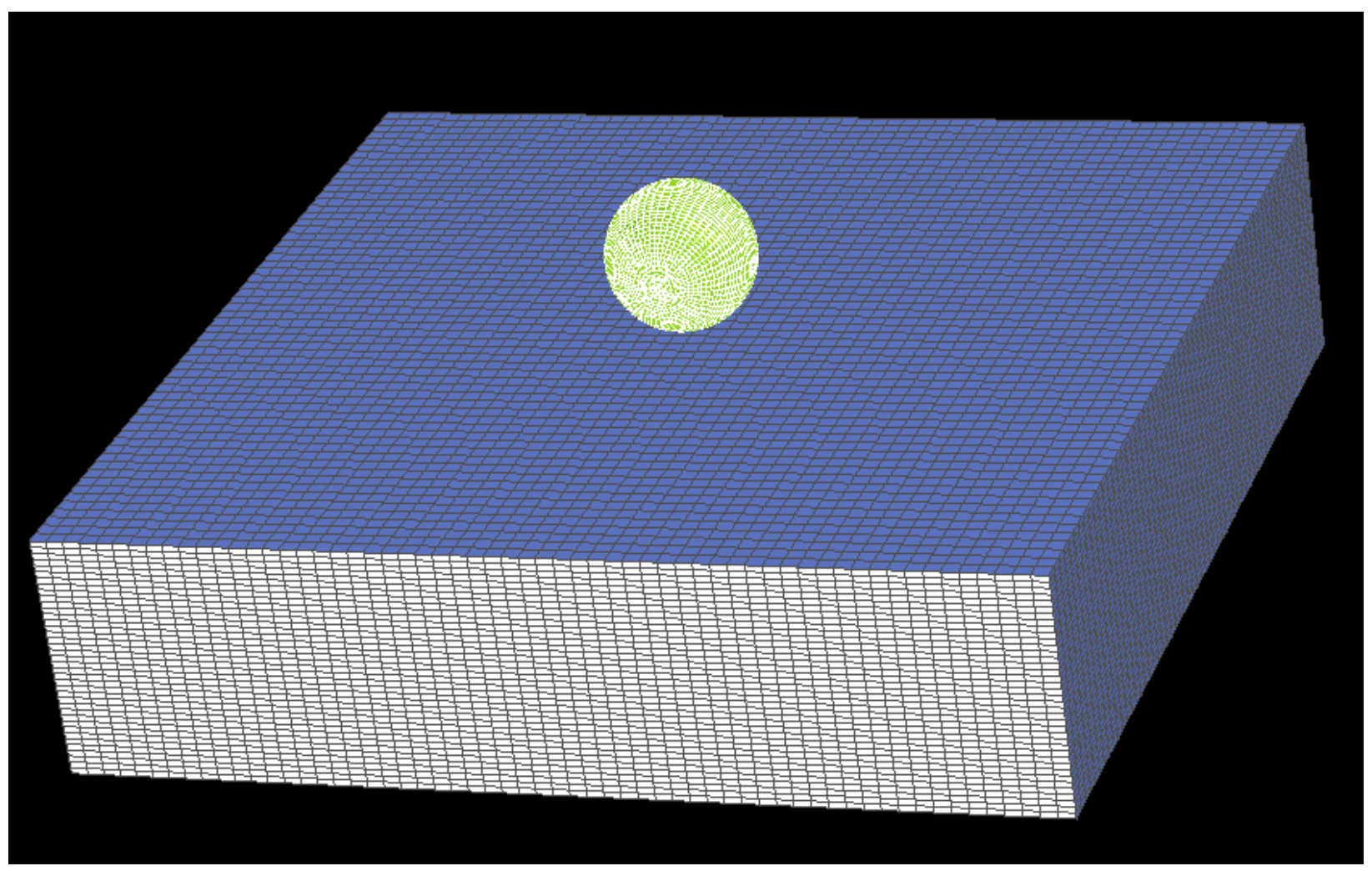

Figure 5.1: Both the sphere and the target were meshed using TrueGrid. 


\section{Model Tuning and Comparison to Test Results}

\section{Type 3 Target Model with Initial Properties}

The deformation of the projectile and a type 3 target model, for an impact velocity of $550 \mathrm{~m} / \mathrm{s}$, and with untuned properties is shown in Figure 5.2. Note that there is only a modest degree of plastic deformation in the target accompanied by only modest velocity slowdown.

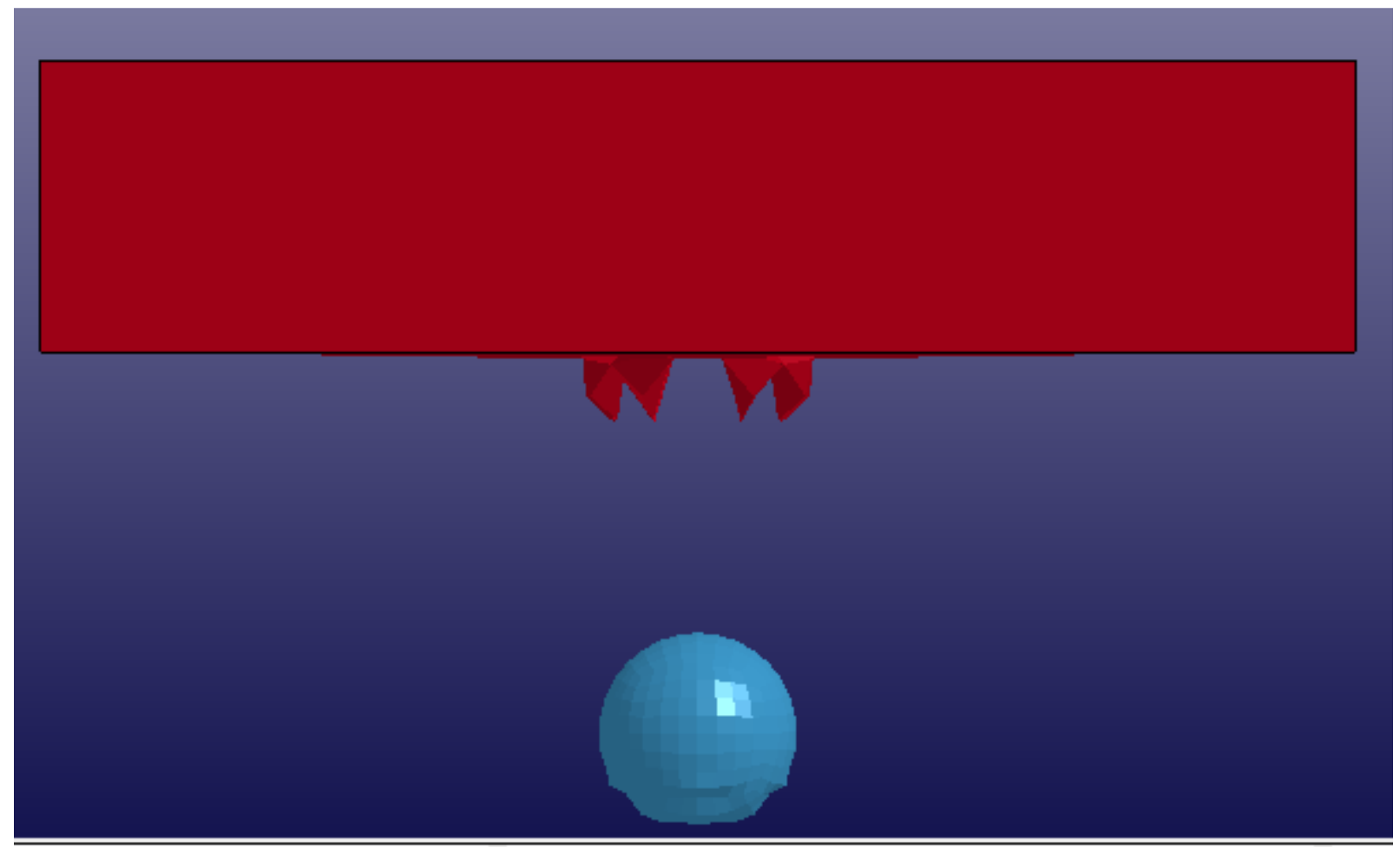

Figure 5.2: Type 3 target model $4.8 \mathrm{~ms}$ after impact shows limited plastic deformation in the target material.

As one might expect, the type 3 model does not adequately replicate the deformation and projectile slowdown that was observed experimentally. A section through the mid-plane of the type 3 simulation is shown In Figure 5.3. Note that aside from the hole punched in the center, there is essentially no plastic deformation. A plot of the projectile velocity is shown in Figure 5.4, showing only modest velocity slowdowns at impact velocities near the V50 for this material. 


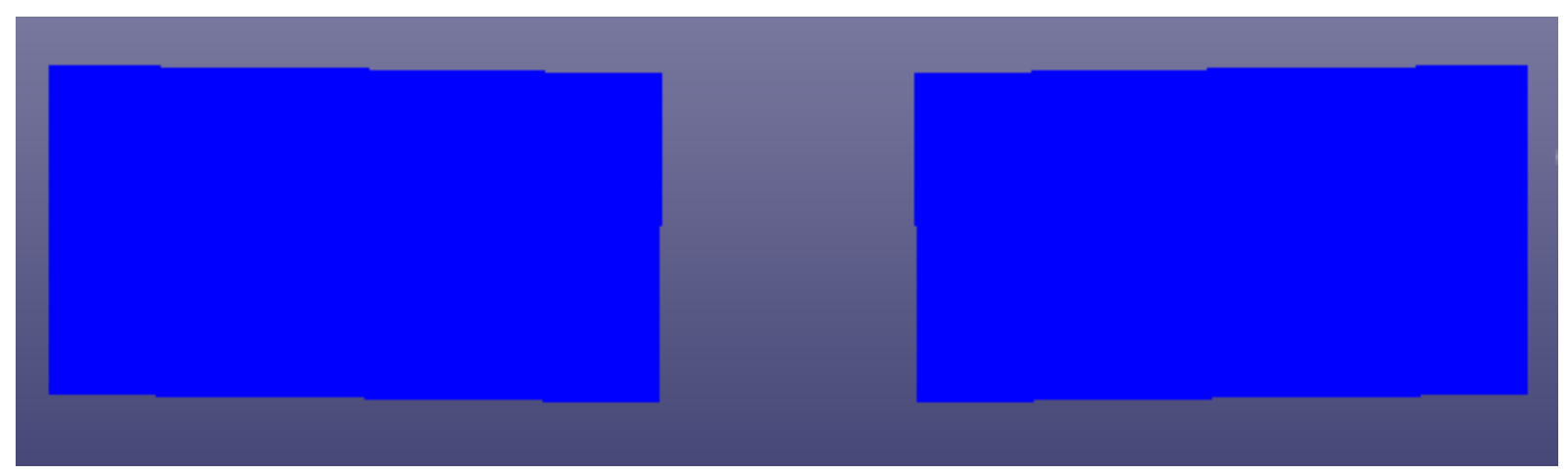

Figure 5.3 : Plot of deformation of the type 3 target at $t=4.8 \mathrm{~ms}$ after impact. Section through $\mathrm{Y}-\mathrm{Z}$ midplane of the target.

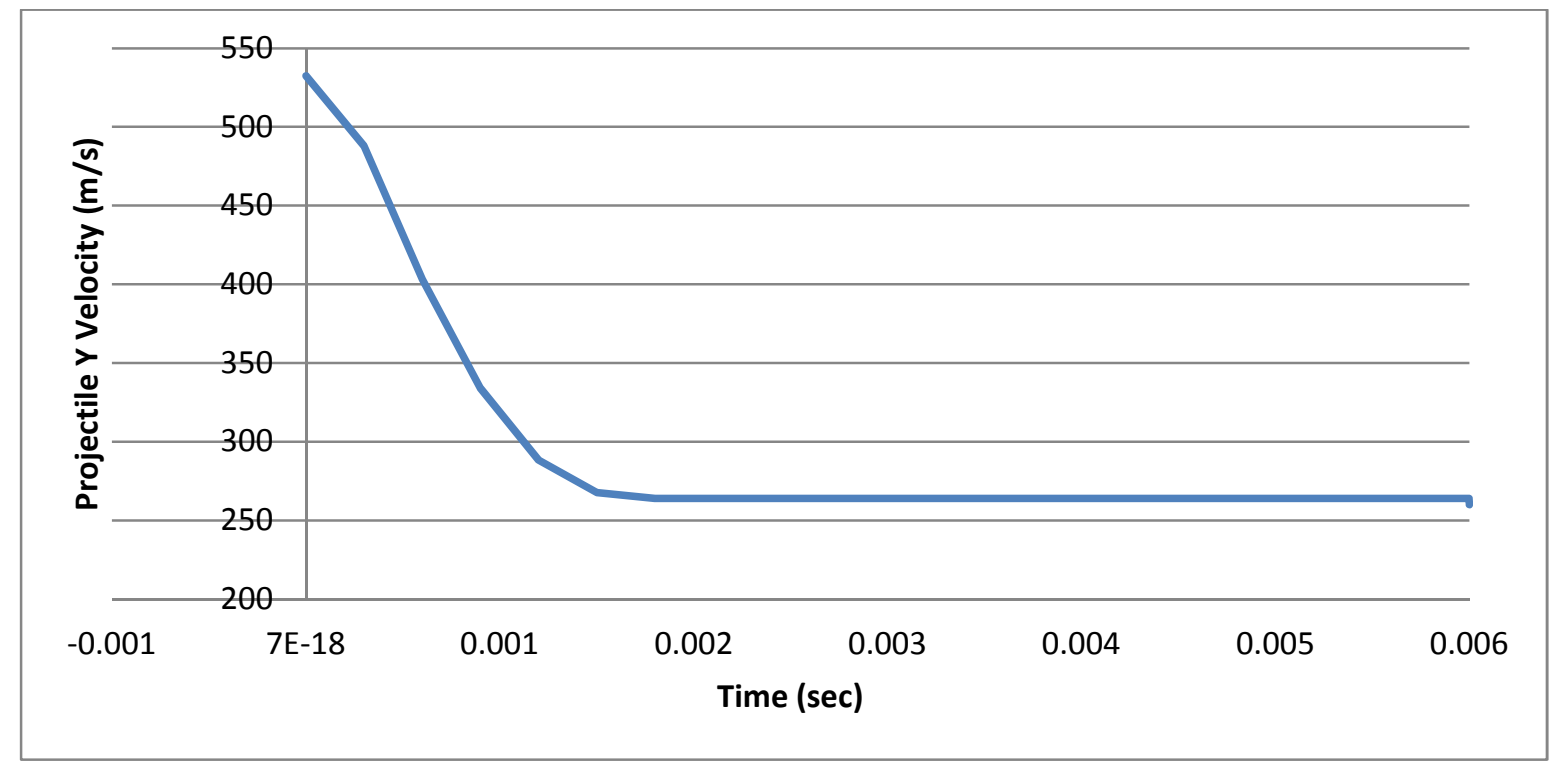

Figure 5.4: Projectile velocity as a function of time for the untuned type 3 model

\section{Type 3 Target Model with Tuned Properties}

In an effort to improve results with the type 3 model, the elastic modulus, yield stress and failure strain were adjusted. These properties were tuned until the model's final state barely defeated the projectile, Figure 5.5. It is notable that there is still very little plastic deformation and no mechanistic match to the experimentally observed delaminations and composite 'blossoming'. 

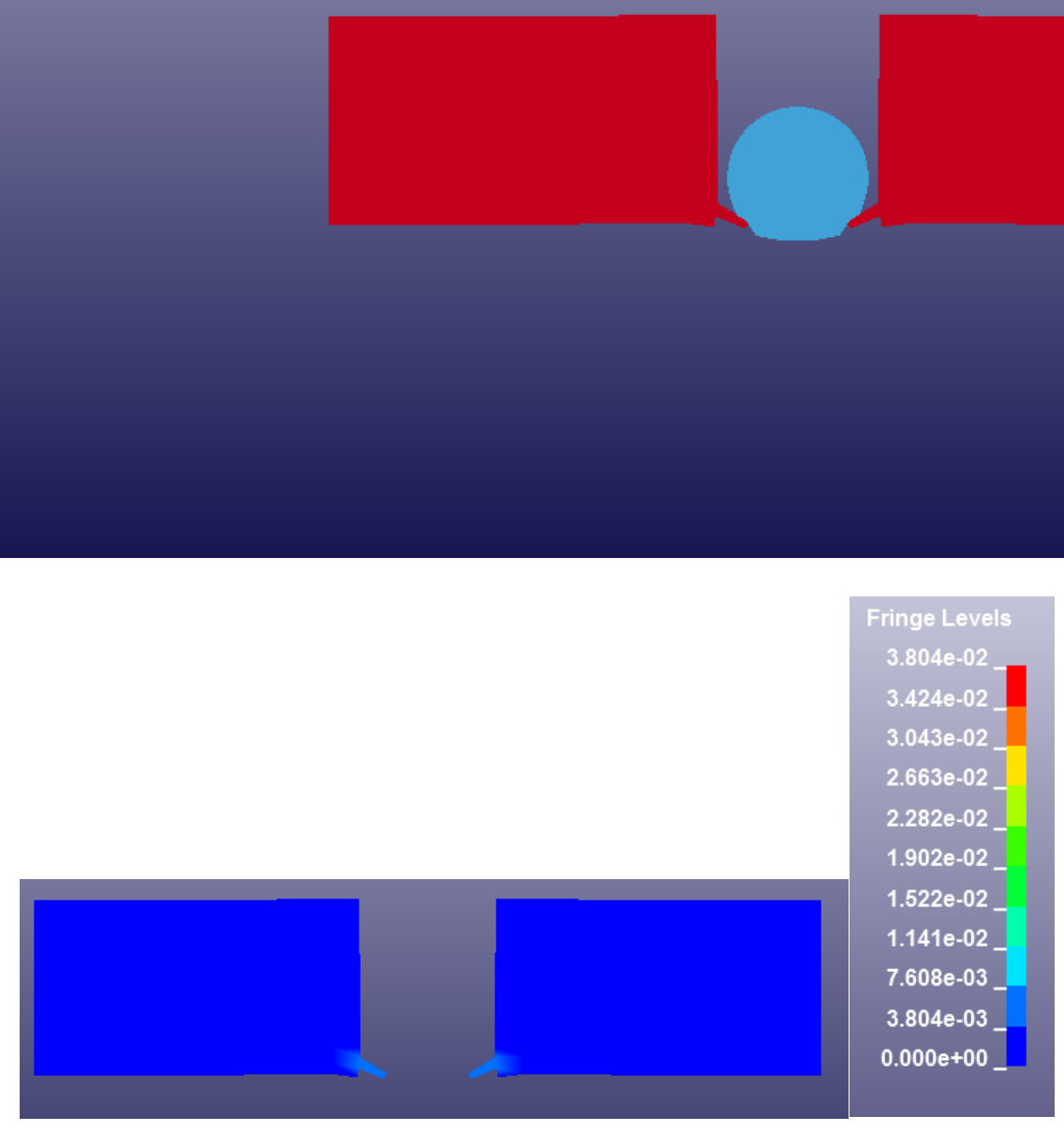

Figure 5.5: LSDYNA simulations of ballistic impact of a stainless sphere and a type 3 plate show little permanent plastic deformation and do not match the experimentally observed response of the composite armor.

Type 59 Target Model with Initial Properties

Since the type 3 model so poorly matched the experimental observations, we conducted a second set of simulations using a type 59 model for the composite armor. Using the initial properties contained in 
Table 5.1 , the simulations produced in a shear punch-out deformation, Figure 5.6.

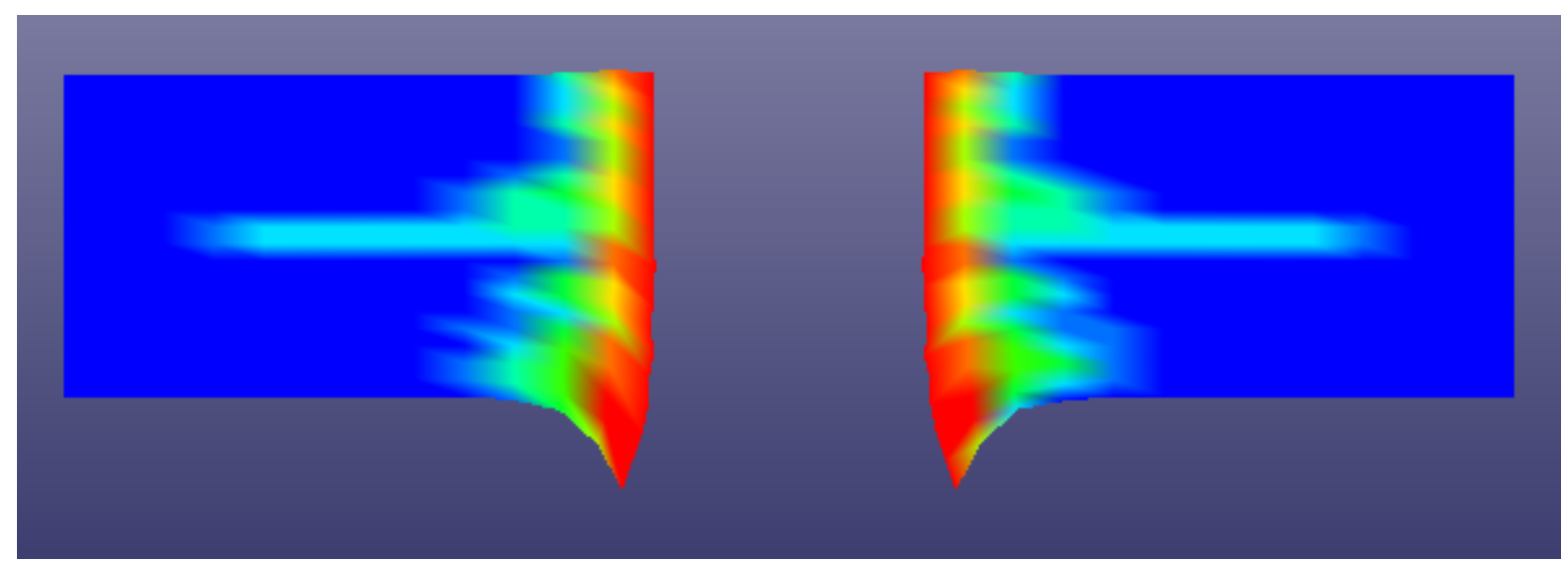

Figure 5.6: Fringes showing plastic strain on the type 59 model with untuned material properties

These results are still vastly different from the experimental results, but did show promise for the generous lateral deformation emanating from the penetration hole, Figure 5.6. Even so, these simulations did not match the extensive delamination that was observed over the entire 2 " by 2 " experimental test specimen. Furthermore, the impact velocity used in this model was the V50, $560 \mathrm{~m} / \mathrm{s}$. An accurate simulation should nearly defeat the projectile or have an exit velocity near zero. However, with untuned properties, the projectile exit velocity for the type 59 material was approximately $523 \mathrm{~m} / \mathrm{s}$. This led us to tune the properties to spread damage over a larger area so as to rob more energy from the projectile. This is demonstrated by a decrease in residual velocity, as shown in Figure 5.7 below. 


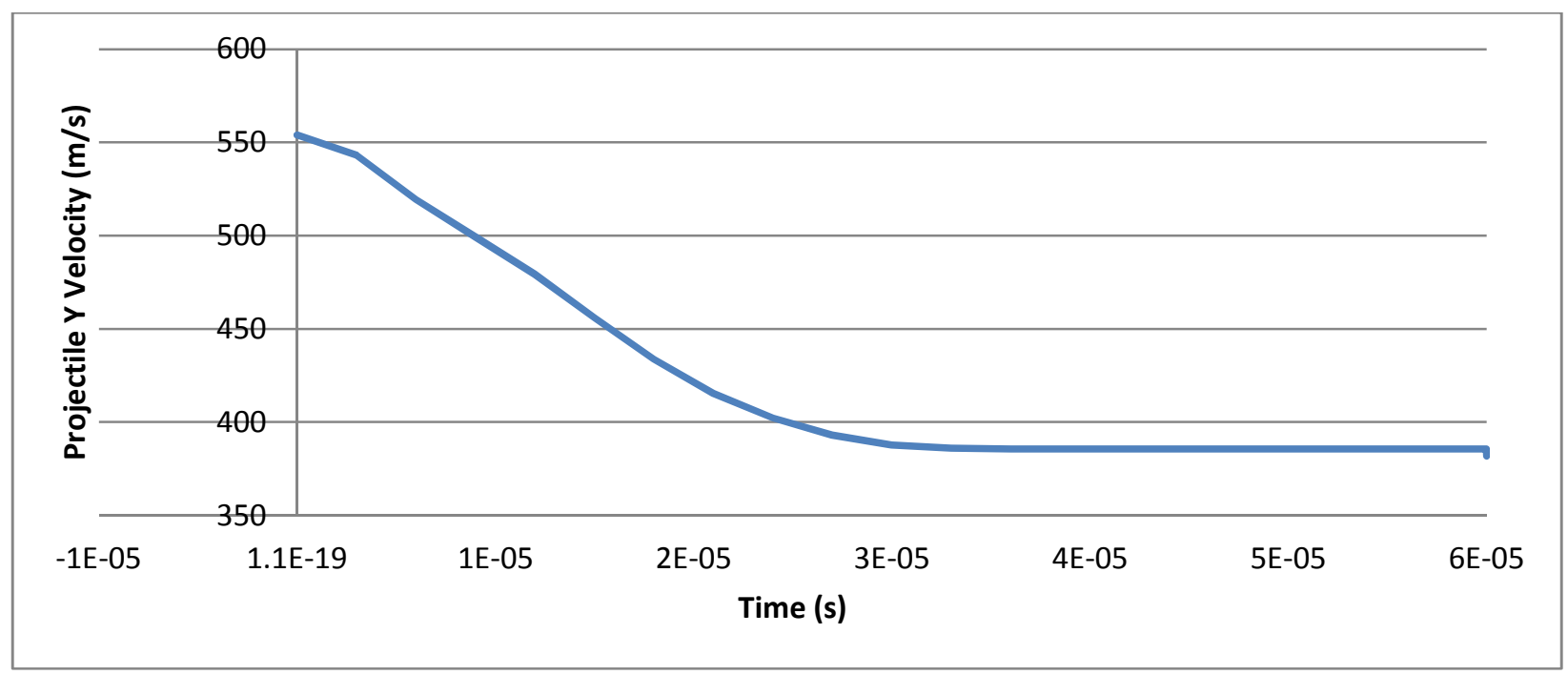

Figure 5.7: Velocity Plot for Type 59 Model with tuned properties

Type 59 Model with Tuned Material Properties

As mentioned above, in order to improve the type 59 model, much more delamination was required. It was felt that reducing the tensile strength in the 3-direction (variable name ZZT) and the in-plane shear stiffness $\left(G_{a b}\right)$ would achieve this, as these properties depend significantly on the matrix material connecting each ply. It was postulated that reducing these properties would cause elements to be more susceptible to a delamination-type failure. Note that the ZZT property is only available in the type 22 and 59 material models with solid elements, which was a major factor in selecting this material type. Results for this adjusted model are shown in Figure 5.8, showing a dramatic increase in both the plastic deformation and the extent of distributed damage. Not surprisingly, this tuning reduced the exit velocity of the projectile to $299 \mathrm{~m} / \mathrm{s}$. 
Figure 5.8: Midplane cross-section of improved model

Table 5.1: Type 59 improved material properties

*MAT_COMPOSITE_FAILURE_SOLID_MODEL

\begin{tabular}{|c|c|c|c|c|c|c|c|}
\hline mid & ro & $\mathrm{Ea}$ & $\mathrm{Eb}$ & Ec & PRba & PRca & PRcb \\
\hline snl/in3 & psi & psi & psi & & & & \\
\hline 2 & $1.82 \mathrm{E}-04$ & $2.00 E+06$ & $2.00 E+06$ & $9.43 E+05$ & 0.35 & 0.08 & 0.08 \\
\hline Gab & $\mathrm{Gbc}$ & Gca & Kfail & AOPT & MACF & & \\
\hline psi & psi & psi & psi & & & & \\
\hline $3.00 \mathrm{E}+05$ & $5.80 \mathrm{E}+05$ & $5.80 \mathrm{E}+05$ & $1.12 \mathrm{E}+06$ & 2 & 1 & & \\
\hline$X P$ & YP & ZP & A1 & $\mathrm{A} 2$ & $\mathrm{~A} 3$ & & \\
\hline 1 & 0 & 0 & & & & & \\
\hline V1 & V2 & V3 & D1 & D2 & D3 & BETA & \\
\hline 0 & 0 & 1 & & & & & \\
\hline SBA & SCA & SCB & $\mathrm{XXC}$ & YYC & ZZC & & \\
\hline psi & psi & psi & psi & psi & psi & & \\
\hline $2.00 \mathrm{E}+03$ & $6.00 \mathrm{E}+04$ & $6.00 \mathrm{E}+04$ & $3.75 \mathrm{E}+04$ & $3.75 E+04$ & $2.00 \mathrm{E}+05$ & & \\
\hline XXT & YYT & ZZT & & & & & \\
\hline psi & psi & psi & & & & & \\
\hline $6.00 \mathrm{E}+04$ & $6.00 \mathrm{E}+04$ & $2.00 \mathrm{E}+03$ & & & & & \\
\hline
\end{tabular}


Type 59 Model with Tuned Material Properties and Invariant Node Numbering

Since our projectile impact velocity was set at $560 \mathrm{~m} / \mathrm{s}$, we aimed to tune the material properties to drive the exit velocity to zero. After extensive tuning of properties, however, we achieved an exit velocity of $270 \mathrm{~m} / \mathrm{s}$. This result was achieved through altering material parameters for the target, as well as turning on the Invariant Node Numbering (INN) option in LSDYNA. In order to ensure that material axes are more accurately updated, the publisher of LSDYNA, Livermore Software Technologies Corporation (LSTC), recommends that this option be used when dealing with deformed composites. Figures 5.9 and 5.10, courtesy of LSTC [23], demonstrates the conceptual improvement that can be made by turning on INN.

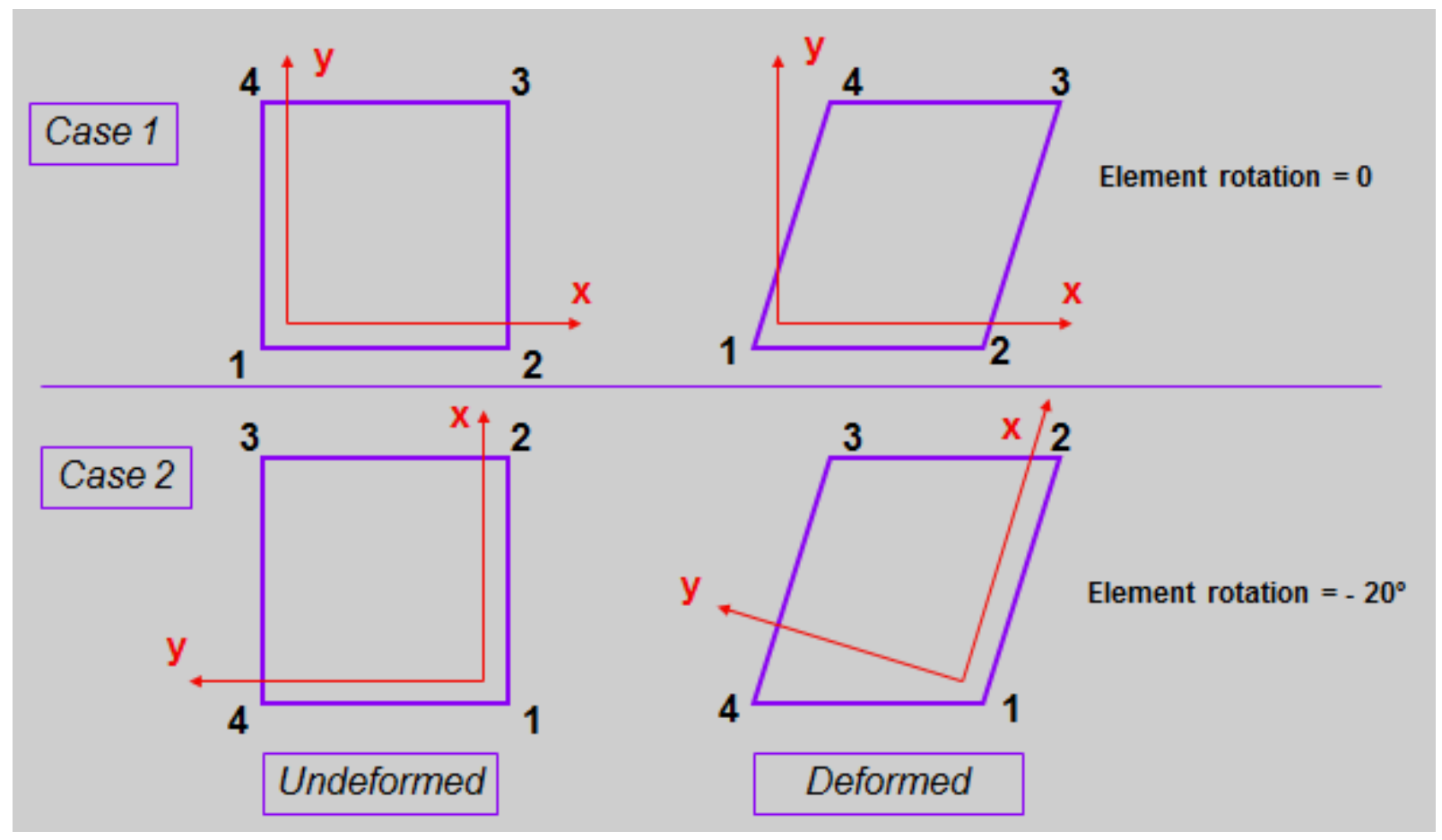

Figure 5.9: Material coordinate axes without INN. Notice how the primary material axes are forced to remain perpendicular, with the $x$-axis in line with the 1 and 2 nodes. This is not a realistic representation of fiber directions in the deformed material. 


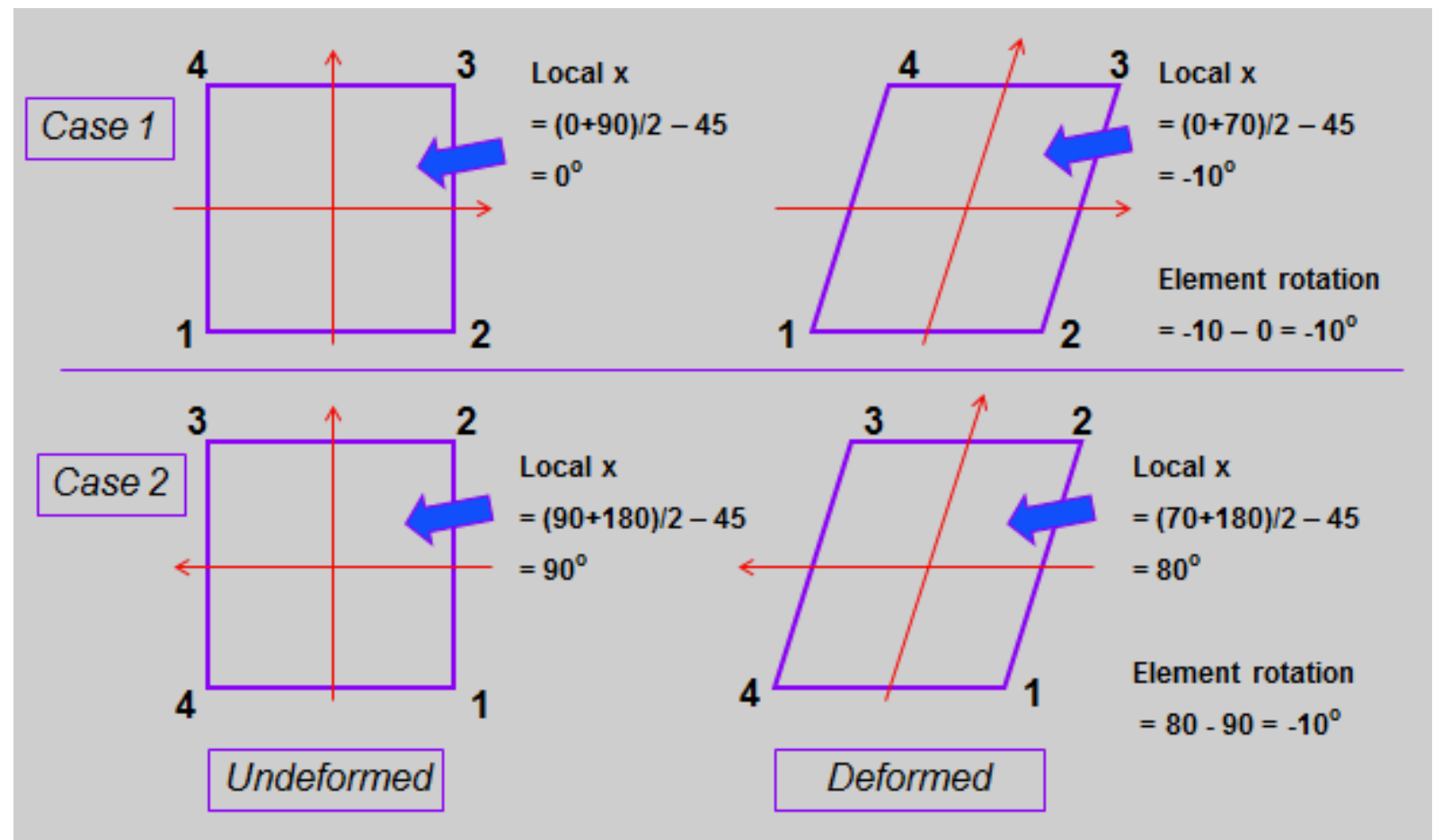

Figure 5.10: Same deformations as before, but with INN turned on. Material directions are now defined by element bisectors, improving accuracy.

INN is turned on within the *CONTROL_ACCURACY card by changing the INN variable from the default value of 1 to 3 (for solid elements). Turning on INN, and making no other changes to the previous best model resulted in a drop in exit velocity to $270 \mathrm{~m} / \mathrm{s}$. Velocity of the projectile CG in the y-direction is shown in Figure 5.11. 


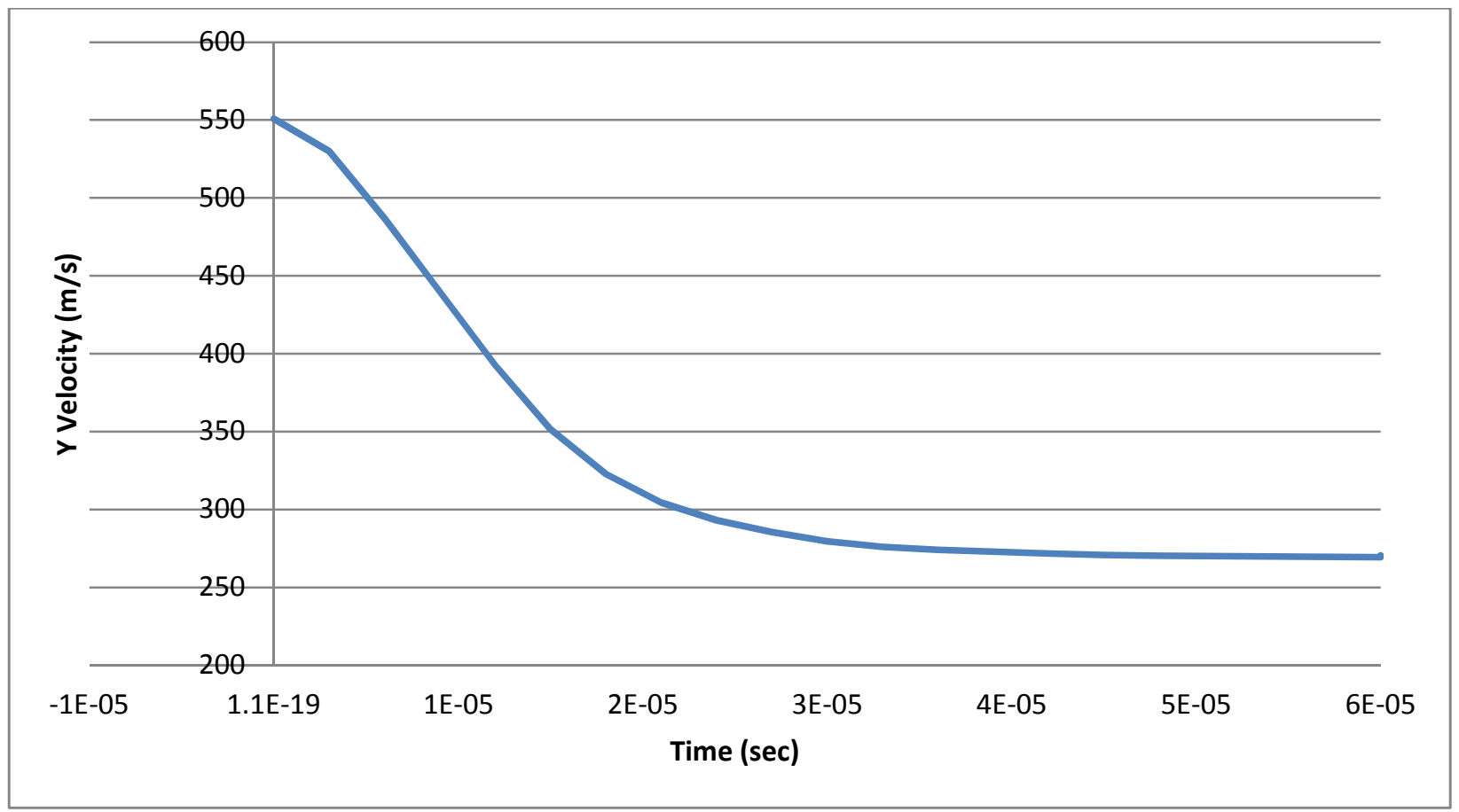

Figure 5.11: Velocity plot for the projectile during and just after the impact event. Nearly all the slowing comes in the first $25 \mu \mathrm{s}$ after impact. Note that exit velocity is still well above the test value near zero.

Final deformation and damage to the target at $\mathrm{t}=6 \times 10^{-5}$ seconds after impact is shown in Figure 5.12. 


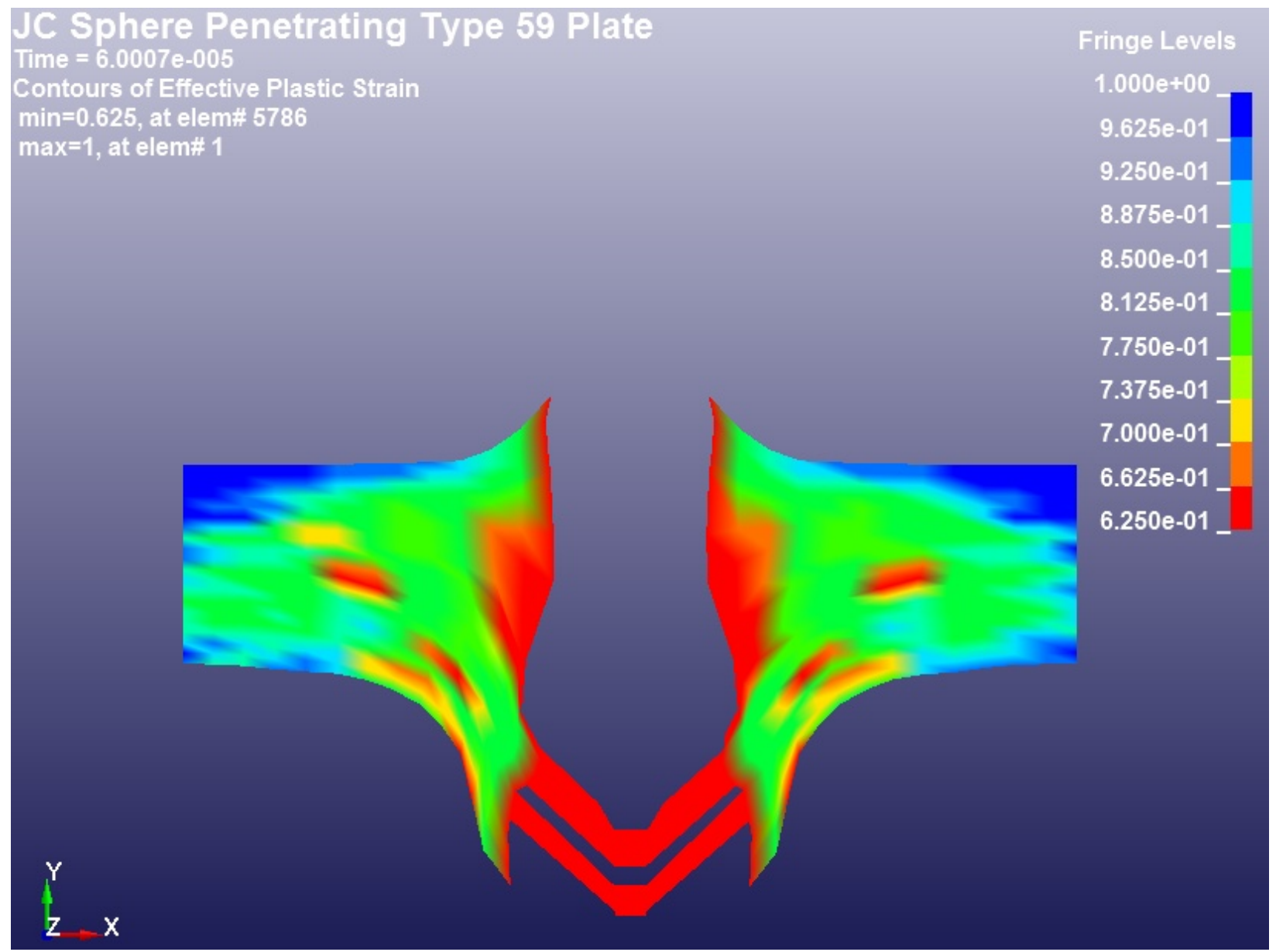

Figure 5.12: Cut-away contour plot of the strain in the model. Note that a strain value of 1 is an undeformed element, while a strain of 0 would indicate a completely failed element.

This model gives results much closer to the experiments than the untuned model, but is still significantly different from the experiments.

One issue with this model is that the deformation of the projectile does not replicate real-world deformation. A comparison of the test projectile from shot number 8 is shown below. This shot had an impact velocity of $549 \mathrm{~m} / \mathrm{s}$, very close to the impact velocity of $560 \mathrm{~m} / \mathrm{s}$ used in this simulation. 

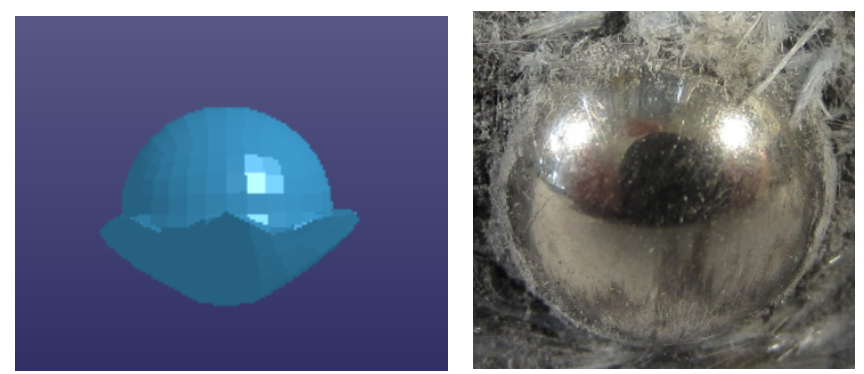

Figure 5.13: The simulated projectile deformation after $6 \times 10-5$ seconds is shown on the left, while the projectile from test shot number 8 is shown on the right. Clearly, the actual projectile experienced much less deformation.

Figure 5.13 above demonstrates how the simulation showed considerably more blunting of the projectile than there was in actual test conditions. It is possible to alter the Johnson-Cook parameters used in order to make the projectile harder, however this may be unrealistic, as the model parameters used were based on extensive tests by UCSB, and are likely to be fairly accurate. Hardening of the projectile was attempted by increasing the constant $\mathrm{A}$ in the Johnson-Cook equation by $10 \%$.

Predictably, this resulted in less (but still significant) deformation of the projectile, and a higher exit velocity of about $298 \mathrm{~m} / \mathrm{s}$. Screenshots of the deformation predicted by this model are shown in Figures 5.14 to 5.16 below. 


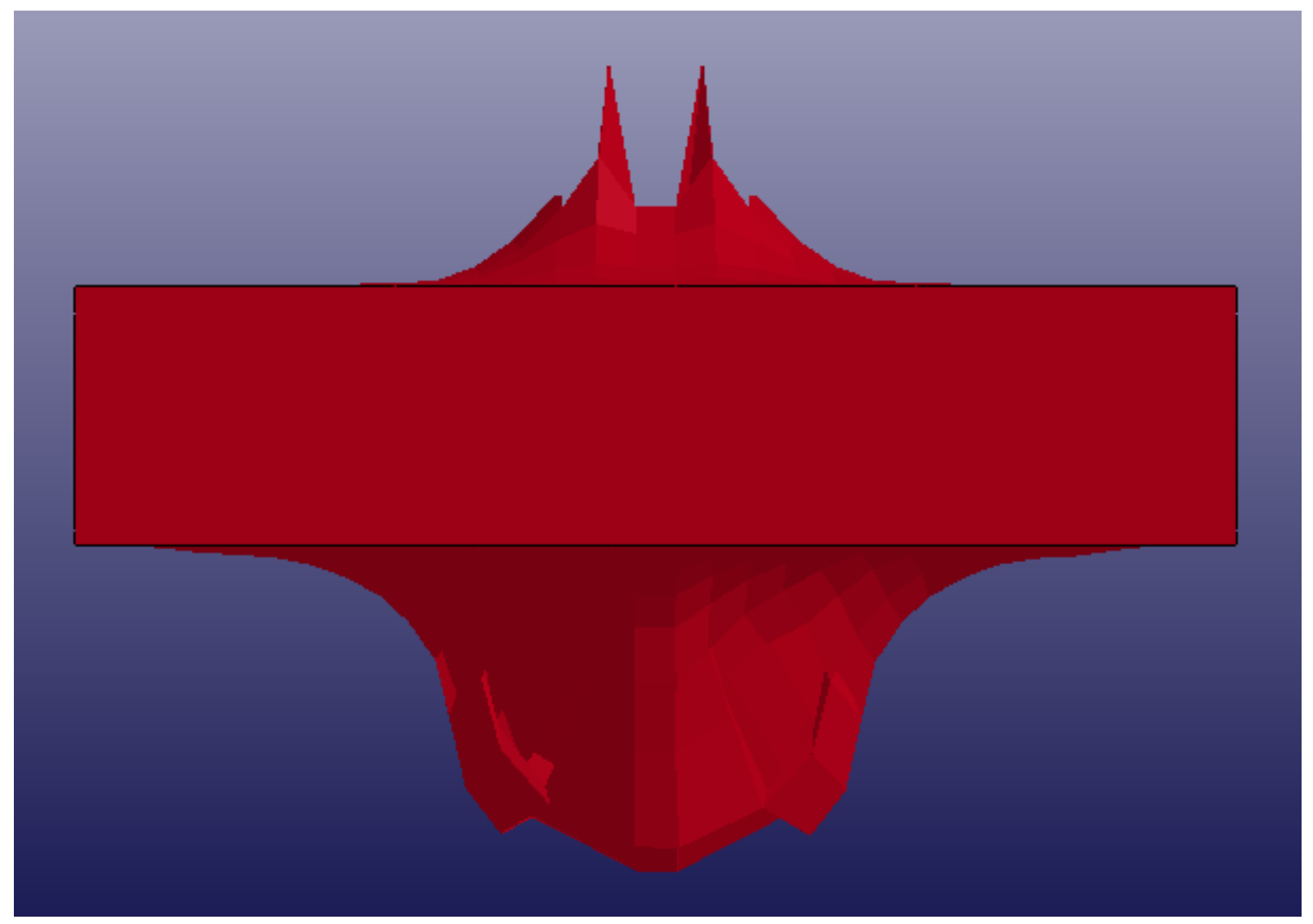

Figure 5.14: Side view of modeled target deformation. Modeling parameters for the target and projectile have been changed significantly. 


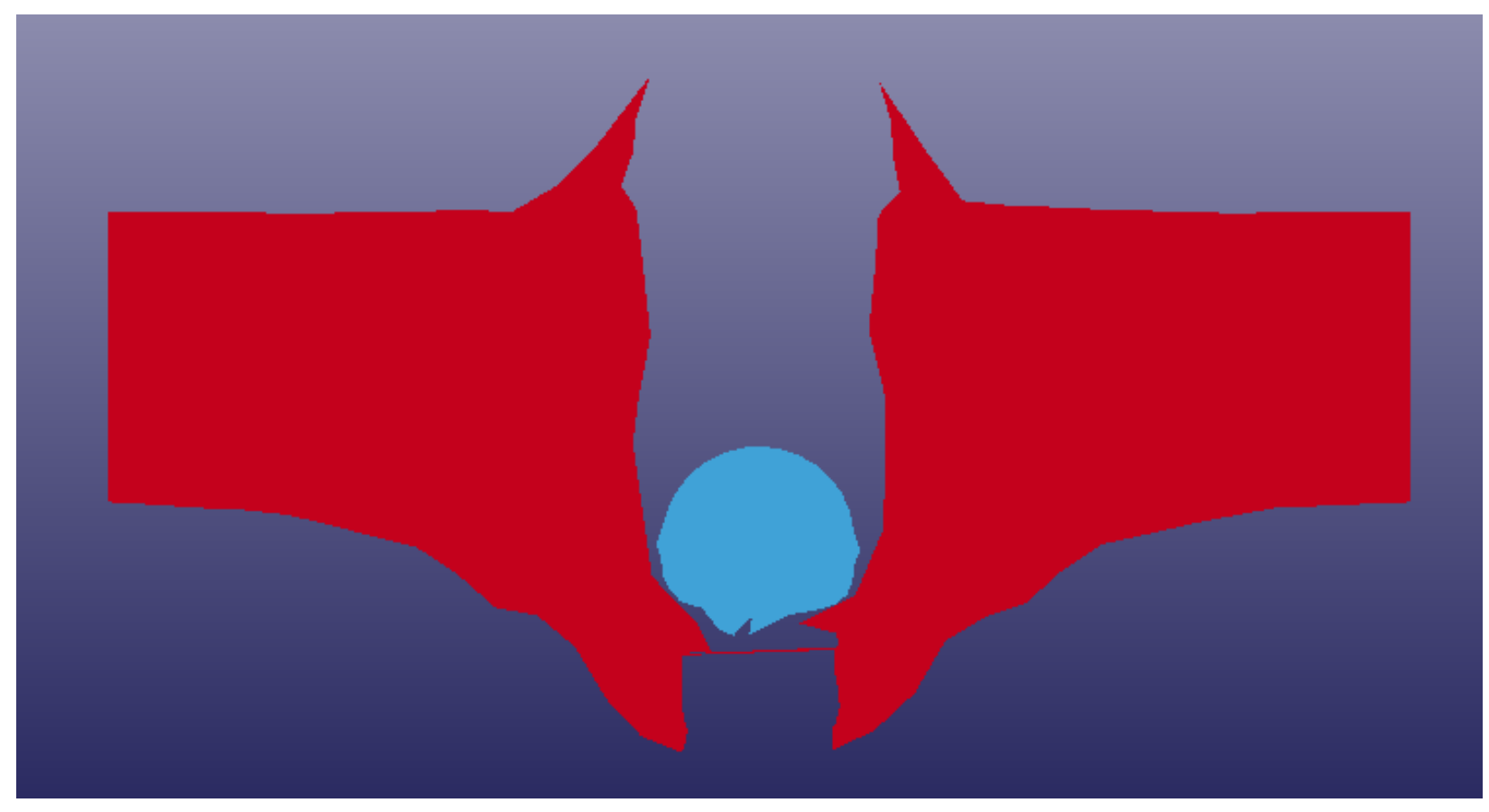

Figure 5.15: Section cut through midplane of the model

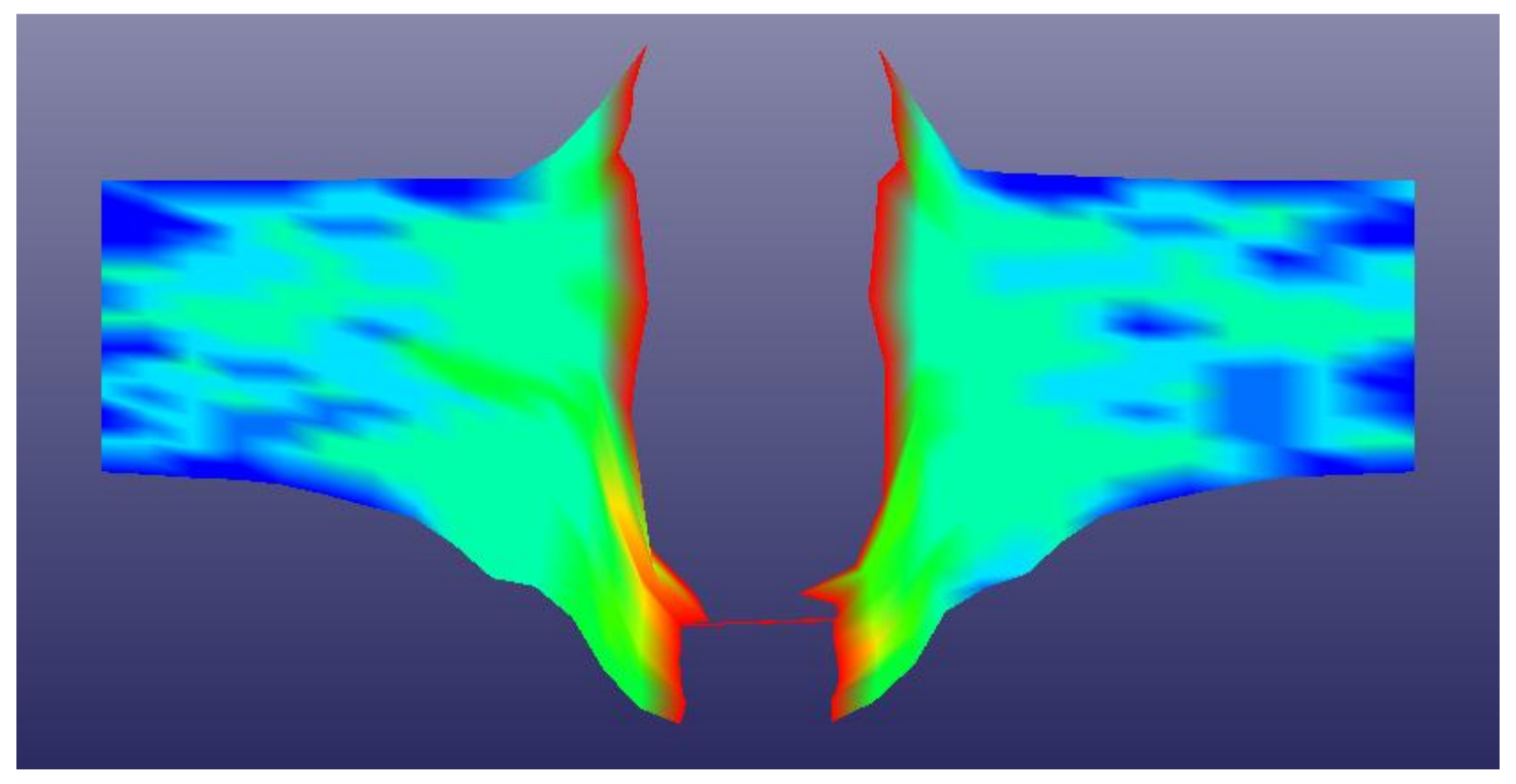

Figure 5.16: Section cut of midplane of model. Fringes show levels of plastic strain.

\section{Conclusions and Recommendations}


The models developed in this study did not accurately predict the energy absorbed by the target plate when modeled using established material properties of the target. By altering properties in the model, accuracy was improved, but model results still differed significantly from physical tests. Based on this, these models would not likely be useful to predict failure of fiber-reinforced composites in ballistic impact. However, with a few changes in model methodology, predicting results from cases like this may be possible.

According to a presentation prepared by LSTC, there are two models, both more complex than those presented in this study, which could do a better job of simulating the behavior of the target, particularly in the area of delamination. In the type 59 models used in this study, there is only one type of element which is used to model failure in both the matrix and in the fibers. Although the material models have multiple failure modes built in, this type of failure criteria may be too simplistic.

The proposed models have two different methods of simulating delaminations. One method is to create layers of 'matrix' elements between each layer of 'fiber' elements. These two element types will each have failure properties associated with their respected materials. The other method is to have several layers of shell elements through the thickness of the target. Then, the NODE_TO_NODE_TIEBREAK card in LSDYNA to bond each layer together. This TIEBREAK constraint has a failure criteria based on in-plane shear and tension [11]. These criteria can be used to simulate the failure properties of the matrix material, and thereby simulate delamination between each ply with the additional benefit of not requiring through-thickness properties due to the use of shell elements. The LSTC presentation says that as yet, there is no clear favorite on which method gives more accurate results.

Due to the relative simplicity, the TIEBREAK model appears to have some advantages. Since fewer tests need to be done (especially the more complex ones finding through-thickness properties) this model is easier to form. Additionally, there is no physical space taken up in the model by the simulated matrix, 
which eliminates an additional tuning parameter that would be difficult to correlate to any real-world measurement, as it is difficult to measure an exact thickness of the matrix layers. This model is also easy to setup in LSDYNA, and due to its use of shell elements in the target, fewer computations are required. In additional work, it is recommended that this model be implemented and compared with experiment.

\section{Appendix A}

\section{Target Drawing}

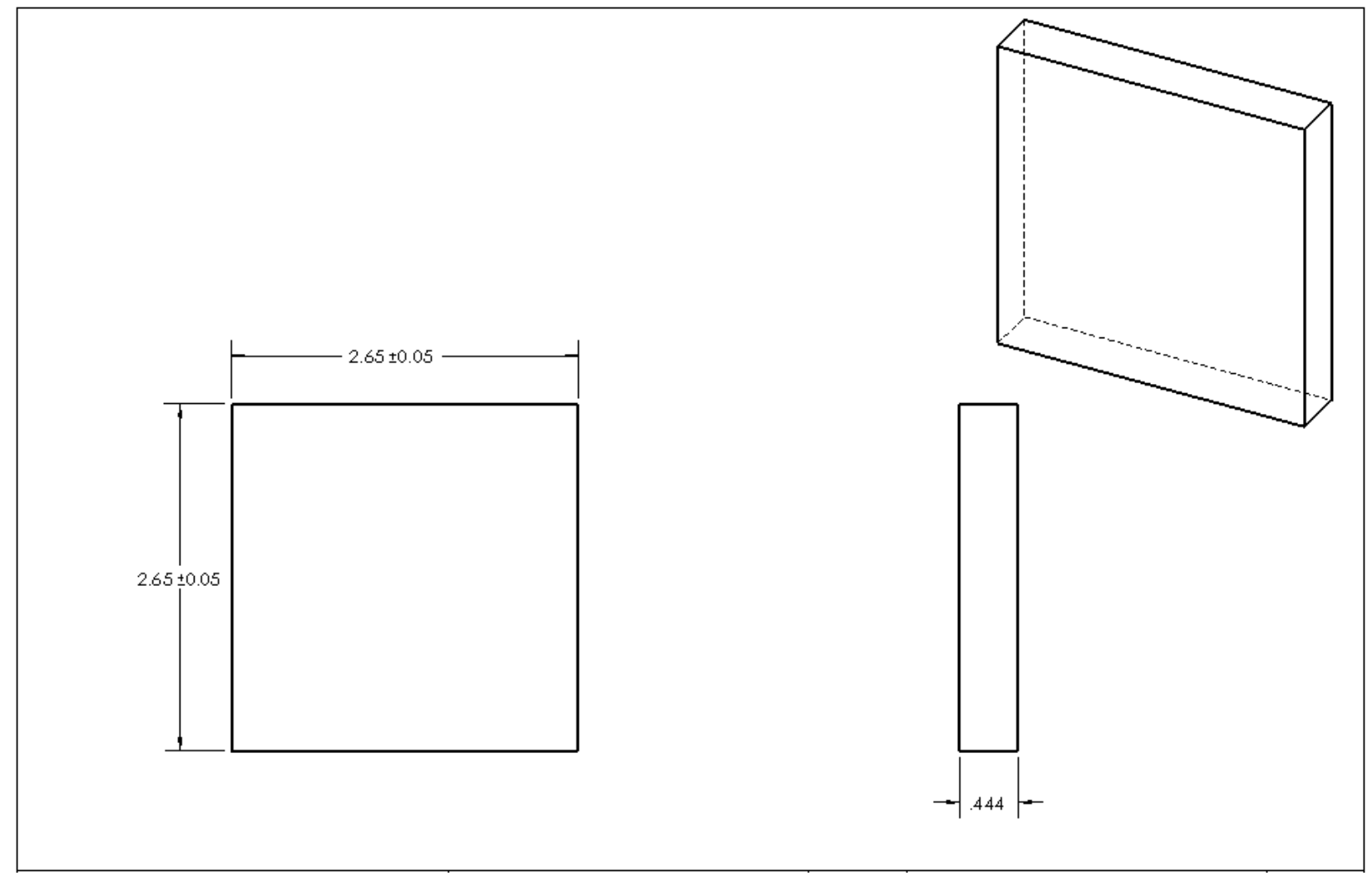

Dimensions are in inches

\section{Appendix B}

Formulations for the failure criteria used for the type 59 material model. When any of the criteria below are true, the material is said to have failed in the corresponding mode. [24]. 
In the notation used below note that: $\sigma_{12}=\sigma_{4}, \sigma_{23}=\sigma_{5}, \sigma_{13}=\sigma_{6}$

1. Longitudinal tension:

$$
\frac{\sigma_{1}^{2}}{x x t^{2}}+\frac{\sigma_{4}^{2}}{s b a^{2}}+\frac{\sigma_{6}^{2}}{s c a^{2}}>1
$$

$\left(\sigma_{1}>0\right)$

2. Transverse tension:

$$
\frac{\sigma_{2}^{2}}{y y t^{2}}+\frac{\sigma_{4}^{2}}{s b a^{2}}+\frac{\sigma_{5}^{2}}{s c b^{2}}>1
$$

$\left(\sigma_{2}>0\right)$

3. Through-thickness shear (combined with long. tension):

$$
\frac{\sigma_{1}^{2}}{x x t^{2}}+\frac{\sigma_{6}^{2}}{s c a^{2}}>1
$$

$\left(\sigma_{1}>0\right)$

4. Delamination (through-thickness tension):

$$
\frac{\sigma_{3}^{2}}{z z t^{2}}+\frac{\sigma_{5}^{2}}{s c b^{2}}+\frac{\sigma_{6}^{2}}{s c a^{2}}>1
$$

$\left(\sigma_{3}>0\right)$

5. Through-thickness shear (combined with transverse tension):

$$
\frac{\sigma_{2}^{2}}{y y t^{2}}+\frac{\sigma_{5}^{2}}{s c b^{2}}>1
$$

$\left(\sigma_{2}>0\right)$

6. Longitudinal compression:

$$
\frac{\sigma_{1}^{2}}{x x c^{2}}>1
$$


$\left(\sigma_{1}<0\right)$

7. Transverse compression:

$$
\frac{\sigma_{2}^{2}}{(s b a+s c b)^{2}}+\frac{\sigma_{2}}{y y c} *\left[\left(\frac{y y c^{2}}{(s b a+s c b)^{2}}\right)-1\right]+\frac{\sigma_{4}^{2}}{s b a^{2}}+\frac{\sigma_{5}^{2}}{s c b^{2}}>1
$$

8. Through-thickness compression:

$$
\frac{\sigma_{3}^{2}}{(s c a+s c b)^{2}}+\frac{\sigma_{3}}{z z c} *\left[\left(\frac{z z c^{2}}{(s c a+s c b)^{2}}\right)-1\right]+\frac{\sigma_{6}^{2}}{s c a^{2}}+\frac{\sigma_{5}^{2}}{s c b^{2}}>1
$$




\section{Works Cited}

[1]Barauskas, R., Abraitiene, A., and Vilkauskas., "Modelling of Bullet Perforation of Textile Targets" Structures Under Shock and Impact, Volume 9, 2006, pg. 355-365

[2]Rajan, S.D., Mobasher, B., and Vaidya, A., "LS-DYNA Implemented Multi-Layer Fabric Material Model Development for Engine Fragment Mitigation" $11^{\text {th }}$ International LS-DYNA User's Conference, 2010, pg. 1-47 to $1-58$

[3] Deka, Lakshya., Bartus, Shane., and Vaidya, U. "High Velocity Impact Testing and Simulation of Thermoplastic Composite Laminates" International SAMPE Symposium and Exhibition, 2008, pg. 52-61

[4] Nilakantan, G., Keefe, M., and Gillespie. J., "Simulating the Impact of Multi-Layer Fabric Targets Using a Multi-Scale Model and the Finite Element Method" International Conference on Textile Composites, 2008, pg. 506-515

[5] National Institute of Justice., Ballistic Resistance of Body Armor: NIJ Standard 0101.06, U.S. Department of Justice, Washington D.C., 2008

[6] Iannucci, L., and Donadon, M., "Bird Strike Modeling Using a New Woven Glass Failure" $9^{\text {th }}$ International LS-DYNA User's Conference, 2008, pg. 18-41 to 18-55

[7] Yen, Chian-Fong., "Ballistic Impact Modeling of Composite Materials" $7^{\text {th }}$ International LS-DYNA User's Conference, 2006, pg. 6-15 to 6-27

[8] Sevkat, E., Liaw, B., Delale, F., Raju, B. "A Combined Experimental and Numerical Approach to Study Ballistic Impact Response of S2 Glass Fiber/Epoxy Composite Beams" Composites Science and Technology, 2009, pg. 965-982

[9] U.S. Department of Defense, Department of Defense Test Method Standard: V50 Ballistic Test for Armor, Washington D.C., 1997

[10] Jenq, S.T., Jing, H.S., and Chung, Charles., "Predicting the Ballistic Limit for Plain Woven Glass/Epoxy Composite Laminate" International Journal of Impact Energy Vol. 15 No. 4, 1994, pg. 451-464

[11] Hallquist, John., "LS-DYNA Theory Manual”, Livermore Software Technology Corporation, 2006

[12] Dean, J., Dunleavy, C.S., Brown, P.M., and Clyne, T.W., "Energy Absorption During Projectile Perforation of Thin Steel Plates and the Kinetic Energy of Ejected Fragments", International Journal of Impact Engineering, 2009, pg. 734-743

[13] Mori, L., Lee, S., and Espinosa, H.D., "Deformation and Fracture Modes of Sandwich Structures Aubjected to Underwater Impulsive Loads" Journal of Mechanics of Materials and Structures, Vol. 2, No. 10, 2007, pg. 1981-2007 
[14] Johnson, G.R., and Cook, W.H., "A Constituative Model and Data for Metals Subjected to Large Strains, High Strain Rates, and High Temperatures" Engineering Fracture Mechanics, 1985, pg. 31-48

[15] Compton, Brett., Personal Interview, June 2011

[16] Steinberg, D.J. Equation of State and Strength Properties of Selected Materials, Lawrence Livermore National Laboratory, 1996

[17]Cowper, G.R., and Symonds, P.S., Strain Hardening and Strain Rate Effect in the Impact Loading of Cantilever Beams, Brown University, Division of Applied Mathematics Report, 1957

[18] Azevedo, R., and Alves, M., "Numerical Simulation of Soft-Body Impact on GFRP Laminate Composites: Mixed SPH-FE and Pure SPH Approaches", Mechanics of Solids, 2009, pg. 15-30

[19] Cheng, W. and Hallquist, J., "Implementation of Three-Dimensional Composite Failure Model into DYNA3D", Livermore Software Technology Corporation, 2004

[20]Hallquist, J. Mat 59 Subroutine, http://ftp.lstc.com/anonymous/outgoing/jday/composites, Accessed August, 2011

[21] North American Bulletproof, http://www.nabulletproof.com/Home.php, Accessed May 2011

[22] Jones, R., Mechanics of Composite Materials, Mc-Graw Hill, 1999

[23] Bala, Suri, and Day, Jim,. "General Guidelines for Crash Analysis in LS-DYNA" http://ftp.Istc.com/anonymous/outgoing/jday/faq/guidelines.ppt

[24] Day, Jim. “MAT_59” http://ftp.Istc.com/anonymous/outgoing/jday/composites/mat_59 